\title{
Risk Factors for Crop Health Under Global Change and Agricultural Shifts: A Framework of Analyses Using Rice in Tropical and Subtropical Asia as a Model
}

\author{
S. Savary, A. Mila, L. Willocquet, P. D. Esker, O. Carisse, and N. McRoberts
}

First and third authors: International Rice Research Institute, IRRI/PBGB Division, DAPO Box 7777, Metro Manila, Philippines; second author: Department of Plant Pathology, North Carolina State University, Campus Box 7405, Raleigh 27695; fourth author: Department of Plant Pathology, University of Wisconsin, 1630 Linden Drive, Madison 53706; fifth author: Horticulture Research Center, Agriculture and Agri-Food Canada, 430 Boulevard Gouin, St-Jean-sur-Richelieu, J3B 3EH, Canada; and sixth author: Plant Pathology Department, University of California, Davis 95616-8751.

Accepted for publication 17 January 2011.

\begin{abstract}
Savary, S., Mila, A., Willocquet, L., Esker, P. D., Carisse, O., and McRoberts, N. 2011. Risk factors for crop health under global change and agricultural shifts: A framework of analyses using rice in tropical and subtropical Asia as a model. Phytopathology 101:696-709.

Plant disease epidemiology requires expansion of its current methodological and theoretical underpinnings in order to produce full contributions to global food security and global changes. Here, we outline a framework which we applied to farmers' field survey data set on rice diseases in the tropical and subtropical lowlands of Asia. Crop health risks arise from individual diseases, as well as their combinations in syndromes. Four key drivers of agricultural change were examined: labor, water, fertilizer, and land availability that translate into crop establishment method, water shortage, fertilizer input, and fallow period duration, respectively, as well as their combinations in production situations. Various statistical approaches, within a hierarchical structure, proceeding from higher levels of hierarchy (production situations and disease syndromes) to lower ones (individual components of production situations and individual diseases) were used. These analyses showed that (i) production situations, as wholes, represent very large risk factors (posi-
\end{abstract}

ABSTRACT tive or negative) for occurrence of disease syndromes; (ii) production situations are strong risk factors for individual diseases; (iii) drivers of agricultural change represent strong risk factors of disease syndromes; and (iv) drivers of change, taken individually, represent small but significant risk factors for individual diseases. The latter analysis indicates that different diseases are positively or negatively associated with shifts in these drivers. We also report scenario analyses, in which drivers of agricultural change are varied in response to possible climate and global changes, generating predictions of shifts in rice health risks. The overall set of analyses emphasizes the need for large-scale ground data to define research priorities for plant protection in rapidly evolving contexts. They illustrate how a structured theoretical framework can be used to analyze emergent features of agronomic and socioecological systems. We suggest that the concept of "disease syndrome" can be borrowed in botanical epidemiology from public health to emphasize a holistic view of disease in shifting production situations in combination with the conventional, individual disease-centered perspective.

Additional keywords: Bayesian analysis, climate change, disease prevention, keystone species, logistic regression, research prioritization.
A major outcome of epidemiological research is to produce recommendations for disease management (11). The most apparent method of such recommendation, because it directly benefits producers, is in the form of a warning system that estimates disease risk $(11,20,46)$. There are many warning systems for many crops, which evolve constantly in response to new disease risks, new technologies, and new policies (e.g., for Europe) (71). Recommendations for disease management may be tactical-for example, for potato late blight (47), Botrytis blight of onions (14), grapevine powdery mildew $(12)$, or apple scab $(13,49)$ - or they may be strategic (i.e., based on information available prior to a growing season); for example, for barley yellow dwarf of wheat (28) or Stewart's wilt of corn (26).

This study addresses the contexts where disease management takes place today and those which may occur tomorrow; it addresses "risk" from a broad perspective, with respect to both current needs and future risks that plant diseases may pose. The focus of these analyses is not on a particular disease; rather, they simultaneously consider a range of diseases. We also address

Corresponding author: S. Savary; E-mail address: s.savary@cgiar.org

doi:10.1094/PHYTO-07-10-0183

(C) 2011 The American Phytopathological Society drivers of change that will affect agriculture and plant protection and, therefore, the contexts where epidemiological research and recommendations for disease management will have to remain relevant (74).

Agriculture is changing at an unprecedented pace worldwide, as a result of global change, population growth, and increased constraints on resources $(25,29,38,61,70)$. Meeting the demands for a sufficient, secure, and sustainable food supply into the $21 \mathrm{st}$ century will require the close cooperation of the science and policy domains $(3,25,38,70)$. Recent publications $(38,61)$ discuss the constraints of mobilizing scientific knowledge to inform policies, local to global. In the absence of a formal analytical framework, these reports combine qualitative evaluations of amassed primary literature with heuristic arguments to arrive at conclusions, relying on a process of validation by consent of readers. Lack of an analytical framework enabling formal linkage between science and policy has many causes. Foremost is that the typical scales of interest in the two fields are markedly different. In trying to use research results to address resource allocation issues, policy analysts confront the task of making inferences at large (regional or global) scales using data pertaining to small (farm or field) scales. This mismatch results in a mutually reinforcing negative feedback between theory and practice. Although the dearth of large-scale data hampers theoretical devel- 
opment, the absence of a theoretical framework hampers suitable empirical studies. Yet, recent conceptual advances in the fields of measurement and information theory show that a small number of generic rules do link stochastic measurements made at low hierarchical levels with the emergent probability distributions, which define the observed properties of a system at higher levels of organization $(31,32)$. These rules, combined with the capacity of hierarchical systems theory to explain large-scale patterns in complex systems (44), provide the framework for studying sustainability in agriculture and food security (36). These methodological developments are essentially an application of the philosophy of methodological individualism, which has proved successful in a wide range of disciplines, from economics, where it originated (4), to population demography (17), or ecological population dynamics (75).

In order to inform policies about future food security, crop loss assessment, largely an ex-post, observational science, has to become predictive (67). This article is a first contribution to that development.

Rice and its diseases constitute an ideal model crop to address the issue of assessing current and future research needs in crop loss and epidemiology, because of (i) the central role of rice in global food security $(27,89)$, (ii) the range of ecological and social contexts where rice production takes place (39), (iii) the impacts that global changes will have on production systems and options to adapt them in a sustainable manner (15), (iv) the importance of rice diseases as yield-reducing factors (estimated losses to diseases in rice are 10 to $20 \%$ of the attainable yield) $(56,67)$, and (v) the existence of large-scale farmers' field survey data that can be mobilized for analysis.

Scarcer resources for agricultural production $(78,80)$ translate into four major drivers of agricultural change, especially for rice production $(39,64)$. First, labor availability (leading to changes in crop establishment methods) (60); second, water shortage (79) in key rice-production areas (9); third, mineral fertilizer use (which may vary in the future in response to productivity needs and shifts in policies) $(39,80)$; and fourth, agricultural land availability, represented by the duration of fallow periods (80). Changes in these individual components of production situations (PSs) have strong consequences on crop health $(57,88)$. In the case of tropical lowland rice, reduction in labor availability drives a switch from transplanting to direct seeding, which increases weed infestation but reduces sheath blight intensity; water shortage, with its many forms, leads to enhanced brown spot and sheath rot and favors weed infestation but strongly suppresses stem rot; and fertilizer (especially nitrogen) inputs, on the other hand, strongly enhance sheath blight and other diseases, as well as insect pests $(63,64,67,82)$. Increased fertilizer prices may, in turn, lead to a reduction in mineral $\mathrm{N}$ application in many cash-poor rice-production systems, which translates into some diseases becoming more (e.g., brown spot) or less (e.g., sheath blight) important $(63,64,69,88)$. Increasing food demand and a reduction in land availability might also lead to increased pressure to a shortening or removal of fallow periods from rotations, increasing the opportunities for disease carry-over between successive crops, such as vector-borne diseases (5).

Each of these four components of PSs are integral, connected, parts of the agricultural production process. They cannot be disconnected, even though each is affected by different factors, themselves having, in turn, marked spatiotemporal variability (33). Conversely, analyzing the variation of diseases individually in response to production contexts is a daunting task, given the number of organisms to consider. More importantly, even if partly successful, single-pathosystem models would lead to incomplete predictions, likely to overlook potentially critical interactions in a multiple-disease ("pest") system in plants (64) or animals (40). Thus, a hierarchical approach is appropriate, where individual components of production contexts and individual components of multiple disease (pest) systems are considered as parts of larger entities, PSs and disease syndromes (Ss), respectively.

The concept of a PS refers to the biophysical and socioeconomic context under which agriculture takes place $(21,77)$. Thus, PSs include interlinked technological components leading to agricultural performances, positive or negative (77). In plant protection, the PS concept has been operationalized as a vector of qualitative and quantitative variables, including production components (69), as well as strategic and tactical decisions (87). The association between PSs and Ss has been shown in a range of systems, including rice in tropical and subtropical Asia, coffee in Central America, groundnut in West Africa, or wheat in Western Europe (66). The concept of $\mathrm{S}$ has been defined operationally elsewhere $(51,66)$ : it refers to a collection of disease injuries that occur concurrently in a given (individual) field over its crop growth history within a growing season. In this study, we derive the notion of Ss from earlier work (69), where diseases were considered simultaneously with animal pests and weeds. When crop health as a whole is considered, to include injuries caused by diseases, animal pests, and weeds, the term "injury syndrome" is used. Here, we focus on Ss only, which are embedded in injury syndromes.

The ability to accurately predict Ss is needed urgently in plant pathology because the development of management tools which will be required in the future to protect crops from new diseases and Ss entails research that takes at least a decade to translate into practical options, such as seed (and the resistance genes they carry) and others (58).

In pursuit of an integrative approach to deal with the issues just outlined, the analyses carried out in this article fall into three stages. In a first stage, relationships between Ss and PSs were assessed within a hierarchical framework. In a second stage, a predictor for risk of Ss was developed and evaluated. Finally, in a third stage, the predictor was used in scenario analyses where changes in four key rice-production factors were considered to predict shifts in Ss.

\section{MATERIALS AND METHODS}

Background. A new series of analyses was conducted on a data set that was previously used to characterize associations between crop health and PSs in 456 lowland rice farmers' fields in tropical and subtropical Asia (India, the Philippines, Vietnam, and China) (69). These data were collected at the individual farmer's field level, from field measurements of crop status and injuries (diseases, pests, and weeds) at four development stages, along with information on PSs and direct yield estimates $(67,69)$. Data pertaining to each individual field were categorized, and separate hierarchical cluster analyses using a $\chi^{2}$ metric were used to generate groups of fields belonging to the same PSs or to the same syndromes of injuries caused by diseases, pests, and weeds (69). Abridged and summarized results are shown in Table 1 (PSs) and Table 2 (Ss). Cluster analyses left a fraction of fields unassigned for PSs (37 fields, or $8.1 \%$ of the total sample of 456 farmers' fields were included in a category termed "noclassPS") or for injury syndromes (27 fields, or $5.9 \%$, included in a category termed "noclassS"). PSs differed markedly with respect to fallow period duration, crop establishment method, water shortage, and mineral fertilizer inputs. Syndromes of injuries (diseases, insects, and weeds) strongly differed, in particular with respect to six rice diseases: sheath blight (SHB), sheath rot (SHR), brown spot (BS), leaf blast (LB), neck blast (NB), and bacterial leaf blight (BLB). Because injury syndromes are so strongly associated with the injuries caused by these six diseases, the Ss involving these six diseases only can be used as markers of the overall injury syndromes (69).

Major conclusions from earlier analyses can be summarized as follows: (i) despite the diversity of environments and possible 
diseases (and other yield-reducing factors) in rice, over a very large survey area, only a few PSs and a few injury syndromes (Ss) were sufficient to capture these diversities; (ii) PSs and Ss were not site-specific; rather, the same PSs or Ss were found at geographically very distant locations whereas, within localized geographic areas, very different PSs and Ss may occur in close geographical proximity; and (iii) very strong statistical links were indicated between injury syndromes and PSs using $\chi^{2}$ tests and multivariate descriptive methods $(67,69)$.

The results from these analyses can be summarized in a twoway contingency table $(65,69)$, where the columns are injury syndromes (S1 to S5) and the rows are PSs (PS1 to PS6). Entries in the resulting contingency table are partitioned distribution frequencies (i.e., counts of the number of fields which belong to each possible pairwise combination of $S$ and PS classes). This table represents information at the highest hierarchical level about the correlation between injury syndromes and PSs.

If the numbers of fields in the cells of the table occur at random, then no statistical linkage between the two factors is indicated, and knowledge of one would provide no predictive information about the other; a null hypothesis of independence of the two distribution frequencies would not be rejected. Such a null hypothesis, termed $\mathrm{H}_{01}$, was tested previously using a $\chi^{2}$ test $(65,69)$. To establish the conceptual link between the earlier study $(69,67)$ and the present work, we begin by retesting $\mathrm{H}_{01}$ in a generalized linear modeling (GLM) framework, which is then extended in several ways to explore the correlation structure of connections between Ss and PSs at lower levels in the organizational hierarchy. The correspondence analysis approach used by Savary et al. (69) and the log-linear modeling approach employed here have some underlying structural connections (76).
Describing hierarchical relationships between PSs and Ss. We used log-linear modeling (3) to reanalyze the above $\mathrm{H}_{01}$ hypothesis within a GLM framework. Note that, in log-linear models, no distinction is made between explanatory (causal) and response (caused) variables, and one simply examines the capacity of different, usually nested, models to reproduce the observed pattern of cell counts in the contingency table. The standard approach is to specify a maximal model (often this is the fully saturated interaction model for all factors in the cross-classification, but it need not be) against which the ability of simpler models to achieve comparable fits to the data is quantified. The saturated model in a log-linear analysis contains a parameter for each cell in the table and, therefore, reproduces the data exactly. In the current example, which is a two-way classification of fields (PS = $1 \ldots 6 \mathrm{PSs}$ and $\mathrm{S}=1 \ldots 5 \mathrm{Ss}$ ), the saturated model can be written as

$$
\log \left(m_{\mathrm{PSS}}\right)=\mu+\beta_{\mathrm{PS}}+\beta_{\mathrm{S}}+\beta_{\mathrm{PSS}}
$$

in which $\log \left(m_{\mathrm{PSS}}\right)$ is the logarithm of the entry in cell $\left[\mathrm{PS}_{i} \mathrm{~S}_{j}\right] ; \mu$ is the overall mean; the parameters $\beta_{\mathrm{PS}}$ and $\beta_{\mathrm{S}}$ describe the main effects of PSs and Ss, respectively; and the $\beta_{\mathrm{PSS}}$ are the interaction terms between the two classification factors. To test for independence of PS and S in this framework, we specified the saturated model and then examined the deviance ratio test for dropping the interaction term $\beta_{\text {PSS }}$ from the model, resulting in the so-called row column independence model:

$$
\log \left(m_{\mathrm{PSS}}\right)=\mu+\beta_{\mathrm{PS}}+\beta_{\mathrm{S}}
$$

For all further steps of the analysis, we imposed the assumption of causation from PS to S; that is, we adopted the view of PSs and their components as causal variables that may explain the

\begin{tabular}{|c|c|c|c|c|c|c|}
\hline PS descriptor ${ }^{b}$ & PS1 & PS2 & PS3 & PS4 & PS5 & PS6 \\
\hline$n$ & 148 & 6 & 140 & 11 & 81 & 33 \\
\hline \multicolumn{7}{|l|}{ CEM } \\
\hline TR & 68.2 & 100 & 72.9 & 100 & 30.9 & 0 \\
\hline DS & 31.8 & 0 & 27.1 & 0 & 69.1 & 100 \\
\hline WS & $0.6(0.1)$ & $0.8(0.4)$ & $3.7(0.2)$ & $1.3(0.3)$ & $2.5(0.1)$ & $1.9(0.2)$ \\
\hline $\mathrm{MF}$ & $137(6)$ & $100(11)$ & $98(4)$ & $260(12)$ & $133(7)$ & $159(11)$ \\
\hline FP & $137(6)$ & $160(36)$ & $78(2)$ & $3(3)$ & $53(5)$ & $9(1)$ \\
\hline $\mathrm{Y}$ & $4.8(0.1)$ & $4.6(0.2)$ & $3.5(0.1)$ & $6.7(0.3)$ & $3.8(0.1)$ & $3.9(0.3)$ \\
\hline
\end{tabular}

TABLE 1. Main production situation (PS) attributes of rice lowland fields in tropical Asia ${ }^{\mathrm{a}}$

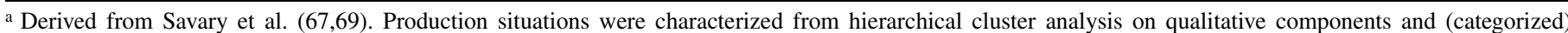
quantitative components of cropping practices and systems. Attributes are not shown for the 37 unclassified fields which were not assigned to one of the six PSs. For water shortage (WS), mineral fertilizer (MF), duration of fallow period (FP), and yield (Y), the average is followed by standard error of the mean in parentheses.

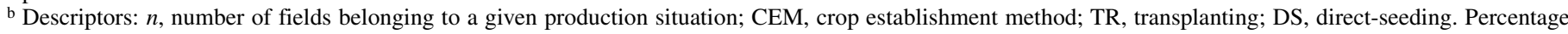
of fields are given for each category of CEM. WS, accumulated WS index over four assessments during the crop cycle; MF, cumulated N, P, and K (kg/ha); FP, duration (number of days); Y, actual (harvested) yield (t/ha).

\begin{tabular}{|c|c|c|c|c|c|}
\hline $\mathrm{S}$ descriptors ${ }^{\mathrm{b}}$ & $\mathrm{S} 1$ & $\mathrm{~S} 2$ & S3 & $\mathrm{S} 4$ & S5 \\
\hline$n$ & 180 & 108 & 123 & 14 & 4 \\
\hline SHB & $12.1(1.3)$ & $6.1(0.8)$ & $9.9(0.9)$ & $17.9(4.7)$ & $0.0(0.0)$ \\
\hline SHR & $1.3(0.2)$ & $3.6(0.8)$ & $7.3(0.5)$ & $6.4(2.4)$ & $0.0(0.0)$ \\
\hline BS & $7(2)$ & $628(89)$ & $727(43)$ & 345 (109) & $216(64)$ \\
\hline LB & $0(0)$ & $49(15)$ & 79 (26) & $0(0)$ & $4(4)$ \\
\hline NB & $0(0)$ & $0.9(0.3)$ & $4.7(0.9)$ & $0.6(0.4)$ & $0(0)$ \\
\hline BLB & $0(0)$ & $75(22)$ & $0(0)$ & $0(0)$ & $0(0)$ \\
\hline $\mathrm{Y}$ & $4.6(0.1)$ & $3.9(0.1)$ & $3.5(0.1)$ & $4.3(0.4)$ & $3.3(0.3)$ \\
\hline
\end{tabular}

TABLE 2. Main injury syndrome attributes of rice lowland fields in tropical Asia, with respect to six diseases (disease syndromes [S])

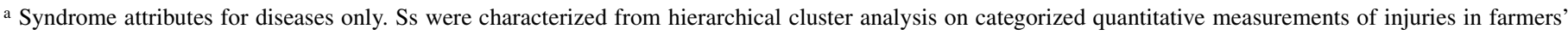
fields $(67,69)$. Attributes are not shown for the 27 unclassified fields which were not assigned to one of the five Ss. For all data except $n$, average is followed by standard error of the mean in parentheses.

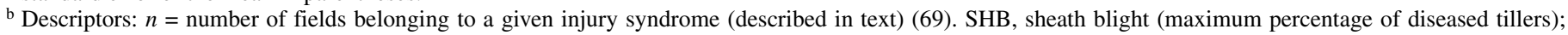
SHR, sheath rot (maximum percentage of diseased panicles); BS, brown spot (area under progress curve of percentage of diseased leaves); LB, leaf blast (area under progress curve of percentage of diseased leaves); NB, neck blast (maximum percentage of diseased panicles); BLB, bacterial leaf blight (area under progress curve of percentage of diseased leaves); Y, actual (harvested) yield (t/ha). 
observed pattern of Ss and their individual components) (i.e., diseases). A series of binary logistic regressions $(1,41)$ were developed to implement these analyses at different levels of hierarchy (2). These were conducted using the unassigned fields for PSs as controls. As already noted, log-linear models and binary logistic regressions fall within the general framework of GLMs. Both types of model have systematic and random components and a canonical link function. For the log-linear model, the random component is assumed to have a Poisson distribution, the systematic component may be mixed (i.e., either categorical, continuous, or both), and the canonical link is the log function. In binary logistic regression, the random component is Bernoulli, the systematic component may be mixed, and the canonical link function is the logit (1).

The first series of logistic regressions were conducted to assess the relationships between Ss and PSs and can be written as $(1,41)$

$$
\ln \left(\frac{P(S=S i)}{(1-P(S=S i)}\right)=\alpha_{i}+\sum_{j=1}^{6} \beta_{i j} P S_{j}
$$

where $i=1 \ldots 5$ and $S_{i}$ are the five Ss. Thus, a separate regression was performed to assess the risk specifically attached to each syndrome; $\alpha_{t}$ is a constant and $\beta_{i j}$ are estimates for each PS (PS1 to PS6). The noclassPS group was used as the control PS category in all five regressions.

Moving down to the [PS - S] hierarchy level, the second series of logistic regressions analyzed relationships between Ss and components of PSs:

$$
\ln \left(\frac{P(S=S i)}{(1-P(S=S i)}\right)=\alpha_{i}+\beta_{i} D S+\gamma_{i} W S+\delta_{i} M F+\varepsilon_{i} F P
$$

where $i=1 \ldots 5$ and $S_{i}$ are the five Ss. Thus, a separate regression was performed to assess the risk specifically attached to each syndrome; $\alpha_{t}$ is a constant; $D S$ represents membership to directseeded crop establishment method (transplanted rice corresponding to the control group); $W S, M F$, and $F P$ are continuous variables representing water shortage, mineral fertilizer, and duration of fallow period, respectively; and $\beta_{t}, \gamma_{t}, \delta_{t}$, and $\varepsilon_{t}$ are estimates for $D S, W S, M F$, and $F P$ factors, respectively.

The third series of analyses considered individual diseases and their relationships to PSs:

$$
\ln \left(\frac{P\left(D_{i}=1\right)}{\left(1-P\left(D_{i}=1\right)\right.}\right)=\alpha_{i}+\sum_{j=1}^{6} \beta_{i j} P S_{j}
$$

where $i=1 \ldots 6$ and $D_{i}$ are binary variables corresponding to the six rice diseases considered (SHB, SHR, BS, LB, NB, and BLB). $D_{i}$ is 1 if disease intensity is above a preset threshold, and 0 otherwise. A separate regression was performed to assess the risk specifically attached to each disease; $\alpha_{t}$ is a constant and $\beta_{i j}$ are the estimates for each PS (PS1 to PS6). The noclassPS group was used as the control PS category in all six regressions.

The last series of regressions addressed the lowest level of [PS - S] hierarchy, and assessed relationships between individual disease epidemic risks and components of PSs:

$$
\ln \left(\frac{P\left(D_{i}=1\right)}{\left(1-P\left(D_{i}=1\right)\right.}\right)=\alpha_{i}+\beta_{i} D S+\gamma_{i} W S+\delta_{i} M F+\varepsilon_{i} F P
$$

where $i=1 \ldots 6$ and $D_{i}$ are binary variables corresponding to the six rice diseases. $D_{i}$ is 1 if disease intensity is above a preset threshold, and 0 otherwise. A separate regression was performed to assess the risk specifically attached to each disease; $\alpha_{t}$ is a constant; $D S$ represents membership to direct-seeded crop establishment method (transplanted rice corresponding to the control group); $W S, M F$, and $F P$ are continuous variables representing water shortage, mineral fertilizer, and duration of fallow period, respectively; and $\beta_{t}, \gamma_{t}, \delta_{t}$, and $\varepsilon_{t}$ are estimates for $D S, W S, M F$, and $F P$ factors, respectively.
Some of the disease thresholds were made dependent on the development of the crop, expressed as development stage units (dsu), of 0 to 100 . The thresholds for each individual disease within Ss were as follows: SHB, maximum SHB incidence on tillers throughout the cropping season $<10 \%$; SHR, maximum SHR incidence on panicles throughout the cropping season $<4 \%$; $\mathrm{BS}$, area under BS incidence on leaves progress curve $<400 \%$ dsu; $\mathrm{LB}$, area under LB incidence on leaves progress curve $<10 \%$ dsu; $\mathrm{NB}$, maximum NB incidence on panicles throughout the cropping season $=0 \%$; BLB, area under BLB incidence on leaves progress curve $<10 \%$ dsu. Thus, binary logistic regression was used to model the probability of individual diseases exceeding a plausible damage threshold, with the individual PS components used as the predictors (68).

All analyses were performed with the LOGISTIC procedure of SAS (version 9.1; SAS Institute Inc., Cary, NC) and SYSTAT (version 11; San Jose, CA) (73). For all logistic regressions, the likelihood ratio and its associated probability provided an overall criterion of model suitability. The area under the receiver operating characteristic (ROC) curve was used to assess the predictive ability of the models (41). Predictors were categorical (PSs and crop establishment methods) or continuous (water shortage, mineral fertilizer, and fallow period). Furthermore, predictors could represent risk factors for disease epidemics or Ss (factors with positive parameter estimate), or "risk factors" for nonepidemics, or for nonoccurrence of the syndrome (i.e., factors with negative parameter estimates). In order to facilitate comparison of the effects of these different predictors, corrected odds ratios were first computed for the continuous variables as (41)

$$
\operatorname{corOR}_{i}=e^{\beta i(\text { range/2) }}
$$

where $\operatorname{corOR}_{i}$ is the corrected odds ratio for a given risk factor, $\beta i$ is the parameter estimate for the risk factor, and range is the range of the continuous variable: 4 for water shortage, 300 for mineral fertilizer, and 240 for the fallow period duration.

Second, corrected odds ratios were further computed as $1 /$ corOR $_{i}$ when they were $<1$, so as to be $>1$, and, therefore, represent odds of nonepidemics or odds of nonoccurrence of a given $\mathrm{S}$.

Predicting future rice Ss. A second stage of the analysis dealt with the development of predictive models, using the above four components of PSs as predictors, with Bayesian models (7). This approach was used to reassess the results achieved in the previous stage $(7,41)$ with respect to the roles of components of PS. Thus, these models correspond to one of the relationships addressed in the first stage of the analysis but with one key modification (i.e., the new models were estimated with no constant).

Similar to conventional regression models $(23,73)$, there can be debate on the use of constants in equations for prediction purposes. In the case of logistic regression, one has to consider the importance of constants, reflecting effects not accounted for by predictors (i.e., other components of PSs). These predictors, in this study, as components of PSs (which are necessarily linked within a given PS), or as discrete PSs (which necessarily entail some level of transition, and this is reflected by a fraction of unclassified fields from the PS standpoint), represent a subset of attributes of complex systems. Therefore, when using logistic regressions to predict disease or Ss in the context of new scenarios, one should exert caution in the value that such constants may take and their bearing on interpretation of the estimated parameters $(1,73)$. The constant values would account for new, possibly unpredictable, interactions or clusters (i.e., novel associations among variables). Therefore, we opted for a neutral hypothesis, where constants would arbitrarily be set to zero (1).

Parameter estimate robustness was investigated using Bayesian statistical methods with the Bayesian Using Gibbs Sampling software (WinBugs, version 1.4) (72). Algorithm convergence is an important step in the Gibbs Sampling approach analysis 
because the last $\mathrm{N}$ iterations after convergence are used to obtain estimates of parameter posterior distribution statistics (mean, median, standard deviation, and quantiles) (53). Visual examination of trace plots, autocorrelations, and Gelman-Rubin diagnostic were used to diagnose convergence (35). Runs of 10,000 iterations with dispersed starting values were performed using these convergence criteria. Posterior inference was based on empirical summaries of the final 5,000 samples in each run. Noninformative priors were used for the parameter estimation procedure. To assess the robustness of the estimated model parameters, posterior distributions were visually examined, along with their range or dispersion captured in associated quantiles $(54,55)$. If the posterior distributions are almost equally distributed between negative and positive values, then there is evidence that the data are not informative enough about the sign and the significance of a specific effect. Otherwise, if the distribution lies in the positive or negative direction, the reported data are deemed sufficient to derive robust conclusions about a specific effect. The posterior distributions of the parameter estimates generated with noninformative priors were finally compared with the estimates generated with the standard logistic regression analyses.

Predicting shifts in Ss in response to shifts in components of PSs. In the third and last stage of analysis, the logistic regression models developed in the second stage were used to conduct scenario analyses (62) to predict the likelihood of future Ss as PSs evolve. Four key drivers were chosen as markers of global changes affecting agricultural production in tropical and subtropical Asia (22,39): labor shortage (represented by the shift from transplanting to direct-seeding) $(16,60,64)$, water shortage $(3,6$, $64)$, fertilizer variability $(69,70)$, and land use and cropping intensification (represented by the duration of the fallow preceding rice) $(1,70)$. In each PS, the following changes were considered: crop establishment method, direct seeding versus transplanting; water shortage, increased water shortage from its present mean in each PS to mean +10 and $+50 \%$; total mineral fertilizer input, from their mean in each PS to mean $+10,+50$, and $-50 \%$; and duration of fallow period, from mean in each PS to mean -10 , -50 , and $+50 \%$. The reasons of these choices are primarily related to the fact that three of them (labor, fallow period, and fertilizer) are directly dependent on global markets, local decisions, and policies. These drivers of change are attached to such levels of uncertainty and variability that we chose to use the above ranges rather than a preset, blanket set of scenarios. These scenarios were compared in their outcomes in terms of predicted Ss.

\section{RESULTS}

Description of hierarchical relationships between PSs and Ss. Reanalysis of the highest level association between PSs and Ss confirmed earlier results (69). Removal of the PS-S interaction term from the saturated model generated a change in deviance of 587.33 , a deviance ratio of 29.37 with 20 d.f., which resulted in a significant approximate $\chi^{2}$ test $(P<0.001)$. These results allow us to reject the hypothesis $\left(\mathrm{H}_{01}\right)$ of independence of PS and $\mathrm{S}$.

For simplicity, the results of the different logistic regressions (Tables 3 to 6; Figs. 1 to 4 ) only show estimates corresponding to

TABLE 3. Logistic regressions of occurrence of disease syndromes with production situations (PSs)

\begin{tabular}{|c|c|c|c|c|c|c|c|c|c|}
\hline \multirow[b]{2}{*}{ Syndrome ${ }^{a}$} & \multirow{2}{*}{$\begin{array}{l}\text { Number } \\
\text { of cases }\end{array}$} & \multicolumn{2}{|c|}{ Likelihood ratio } & \multirow[b]{2}{*}{ AUROCC ${ }^{\mathrm{c}}$} & \multicolumn{5}{|c|}{ Parameter statistics by PS ${ }^{d}$} \\
\hline & & LR & $P$ & & PS & Estimate & SE & $P$ & Odds ratio \\
\hline \multirow[t]{3}{*}{$\overline{\mathrm{S} 1}$} & 180 & 330 & $<0.001$ & 0.92 & Constant & -2.110 & 0.529 & $<0.001$ & $\ldots$ \\
\hline & & & & & PS1 & 4.451 & 0.604 & $<0.001$ & 85.9 \\
\hline & & & & & PS4 & 3.091 & 0.859 & $<0.001$ & 22.0 \\
\hline \multirow[t]{5}{*}{$\mathrm{S} 2$} & 108 & 256 & $<0.001$ & 0.92 & Constant & -1.135 & 0.383 & 0.003 & $\ldots$ \\
\hline & & & & & PS1 & -2.029 & 0.566 & $<0.001$ & 0.13 \\
\hline & & & & & PS3 & -2.161 & 0.595 & $<0.001$ & 0.12 \\
\hline & & & & & PS5 & 1.941 & 0.452 & $<0.001$ & 6.97 \\
\hline & & & & & PS6 & 4.601 & 1.085 & $<0.001$ & 99.6 \\
\hline $\mathrm{S} 3$ & 123 & 323 & $<0.001$ & 0.94 & PS3 & 1.153 & 0.382 & 0.003 & 3.17 \\
\hline
\end{tabular}

a Table 2 provides definition of syndromes. Results are not given for S4 and S5, for which no PS significantly contributed to the regressions.

b A case was defined as an individual farmer's field where a given syndrome was observed.

c Area under the receiver operating characteristic curve.

d Table 1 provides definition of PSs. Statistics are given only for constants and PSs having significant $(P<0.05)$ contributions. SE $=$ standard error.

TABLE 4. Logistic regressions of occurrence of disease syndromes with four selected rice production situation (PS) components

\begin{tabular}{|c|c|c|c|c|c|c|c|c|c|}
\hline \multirow[b]{2}{*}{ Syndrome ${ }^{a}$} & \multirow{2}{*}{$\begin{array}{l}\text { Number } \\
\text { of cases }\end{array}$} & \multicolumn{2}{|c|}{ Likelihood ratio } & \multirow[b]{2}{*}{$\mathrm{AUROCC}^{\mathrm{c}}$} & \multicolumn{5}{|c|}{ Parameter statistics by PS component $^{\mathrm{d}}$} \\
\hline & & LR & $P$ & & PS & Estimate & SE & $P$ & Odds ratio \\
\hline \multirow[t]{5}{*}{$\mathrm{S} 1$} & 180 & 258 & $<0.001$ & 0.90 & Constant & -2.509 & 0.502 & $<0.001$ & $\ldots$ \\
\hline & & & & & DS & 0.847 & 0.295 & 0.004 & 2.33 \\
\hline & & & & & WS & -0.775 & 0.092 & $<0.001$ & 0.46 \\
\hline & & & & & MF & 0.008 & 0.002 & $<0.001$ & 1.01 \\
\hline & & & & & FP & 0.026 & 0.003 & $<0.001$ & 1.03 \\
\hline \multirow[t]{3}{*}{$\mathrm{S} 2$} & 108 & 158 & $<0.001$ & 0.86 & DS & 1.051 & 0.282 & $<0.001$ & 2.86 \\
\hline & & & & & WS & -0.183 & 0.092 & 0.046 & 0.83 \\
\hline & & & & & $\mathrm{FP}$ & -0.030 & 0.004 & $<0.001$ & 0.97 \\
\hline \multirow[t]{4}{*}{ S3 } & 123 & 239 & $<0.001$ & 0.91 & Constant & -2.401 & 0.724 & $<0.001$ & $\ldots$ \\
\hline & & & & & DS & -1.846 & 0.329 & $<0.001$ & 0.30 \\
\hline & & & & & WS & 1.357 & 0.162 & $<0.001$ & 5.33 \\
\hline & & & & & $\mathrm{MF}$ & -0.015 & 0.004 & $<0.001$ & 0.99 \\
\hline
\end{tabular}

\footnotetext{
a Table 2 provides definition of syndromes. Results are not given for S4 and S5, for which no component of PS significantly contributed to the regressions.

b A case was defined as an individual farmer's field where a given syndrome was observed.

c Area under the receiver operating characteristic curve.

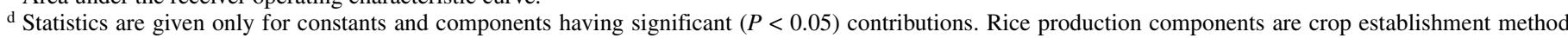
(DS: direct-seeding versus transplanting; statistics given for direct-seeding), water shortage (WS), accumulated water shortage ratings that were taken at four successive observations in each field; mineral fertilizer input (MF), cumulated, total $\mathrm{N}, \mathrm{P}$, and $\mathrm{K}$ inputs for a whole cropping season (kg ha ${ }^{-1}$ ); fallow period duration (FP), delay since the harvest of any crop prior to the observed rice crop (days); $\mathrm{SE}=$ standard error.
} 
constants, classes of categorical variables, or quantitative variables that significantly $(P<0.05)$ contributed to the regression.

Ss and PSs were considered in a first series of analyses pertaining to the highest level of hierarchy. Risks of Ss were very strongly associated with PSs (Fig. 1; Table 3). For instance, there were 85 - and 22-fold increases in the odds of syndrome 1 occurring in PSs 1 and 4, respectively, relative to unclassified fields (i.e., the noclassPS category, used as the control group). The risk for syndrome 2 was increased under PS5 and PS6, while the risk for syndrome 3 was increased with PS3 (odds ratio of 3.2).

The likelihood of occurrence of three different Ss (S1, S2, and S3) associated with different components of PS were then ad-

TABLE 5. Logistic regressions of occurrence of individual rice diseases with production situations (PSs)

\begin{tabular}{|c|c|c|c|c|c|c|c|c|c|}
\hline \multirow[b]{2}{*}{ Disease $^{a}$} & \multirow{2}{*}{$\begin{array}{l}\text { Number } \\
\text { of cases }\end{array}$} & \multicolumn{2}{|c|}{ Likelihood ratio } & \multirow[b]{2}{*}{ AUROCC ${ }^{c}$} & \multicolumn{5}{|c|}{ Parameter statistics by PS ${ }^{d}$} \\
\hline & & LR & $P$ & & PS & Estimate & SE & $P$ & Odds ratio \\
\hline \multirow[t]{3}{*}{ SHB } & 156 & 41 & $<0.001$ & 0.65 & PS4 & 2.357 & 1.099 & 0.032 & 10.6 \\
\hline & & & & & PS5 & -1.277 & 0.427 & 0.003 & 0.28 \\
\hline & & & & & PS6 & -1.927 & 0.627 & 0.002 & 0.15 \\
\hline \multirow[t]{4}{*}{ SHR } & 147 & 137 & $<0.001$ & 0.80 & PS1 & -3.134 & 0.492 & $<0.001$ & 0.04 \\
\hline & & & & & PS4 & -2.575 & 1.100 & 0.019 & 0.08 \\
\hline & & & & & PS5 & -1.258 & 0.415 & 0.002 & 0.28 \\
\hline & & & & & PS6 & -1.411 & 0.525 & 0.007 & 0.24 \\
\hline \multirow[t]{3}{*}{ BS } & 143 & 213 & $<0.001$ & 0.86 & PS3 & 0.909 & 0.378 & 0.016 & 2.48 \\
\hline & & & & & PS5 & -1.019 & 0.436 & 0.019 & 0.36 \\
\hline & & & & & PS6 & 1.364 & 0.515 & 0.008 & 3.91 \\
\hline \multirow[t]{3}{*}{ LB } & 81 & 93 & $<0.001$ & 0.79 & Constant & -0.993 & 0.370 & 0.007 & $\ldots$ \\
\hline & & & & & PS1 & -3.997 & 1.070 & $<0.001$ & 0.02 \\
\hline & & & & & PS5 & -1.218 & 0.525 & 0.020 & 0.30 \\
\hline \multirow[t]{2}{*}{ NB } & 83 & 73 & $<0.001$ & 0.76 & Constant & -1.288 & 0.399 & 0.001 & $\ldots$ \\
\hline & & & & & PS1 & -3.003 & 0.816 & $<0.001$ & 0.05 \\
\hline \multirow[t]{3}{*}{ BLB } & 46 & 37 & $<0.001$ & 0.74 & Constant & -2.428 & 0.602 & $<0.001$ & $\ldots$ \\
\hline & & & & & PS5 & 1.313 & 0.655 & 0.045 & 3.72 \\
\hline & & & & & PS6 & 1.447 & 0.718 & 0.044 & 4.25 \\
\hline
\end{tabular}

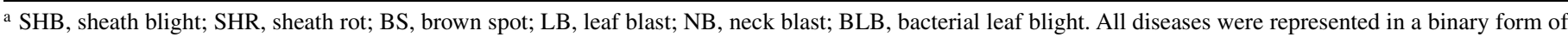
disease intensity as follows: maximum SHB incidence on tillers throughout the cropping season $<10 \%$, SHB $=0$ and $\geq 10 \%$, SHB $=1$; maximum SHR incidence on panicles throughout the cropping season $<4 \%$, SHR $=0$ and $\geq 4 \%$, SHR $=1$; area under BS incidence on leaves progress curve $<400 \%$.day, BS $=0$ and $\geq 400 \%$.day, $\mathrm{BS}=1$; area under LB incidence on leaves progress curve $<10 \%$.day, $\mathrm{LB}=0$ and $\geq 10 \%$.day, LB $=1$; maximum $\mathrm{NB}$ incidence on panicles throughout the cropping season $=0 \%, \mathrm{NB}=0$ and $\geq 0 \%, \mathrm{NB}=1$; area under $\mathrm{BLB}$ incidence on leaves progress curve $<10 \%$.day, $\mathrm{BLB}=0$ and $\geq 10 \%$.day, $\mathrm{BLB}=1$.

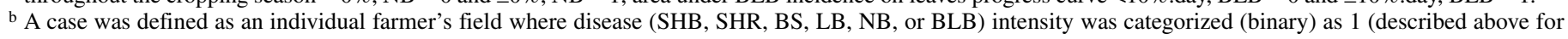
threshold values used), out of 456 fields.

c Area under the receiver operating characteristic curve.

d Table 1 provides definition of PSs. Statistics are given only for constants and PSs having significant $(P<0.05)$ contributions. SE $=$ standard error.

TABLE 6. Logistic regressions of occurrence of individual rice diseases with four selected rice production situation (PS) components

\begin{tabular}{|c|c|c|c|c|c|c|c|c|c|}
\hline \multirow[b]{2}{*}{ Disease $^{\mathrm{a}}$} & \multirow{2}{*}{$\begin{array}{l}\text { Number } \\
\text { of cases }^{b}\end{array}$} & \multicolumn{2}{|c|}{ Likelihood ratio } & \multirow[b]{2}{*}{$\mathrm{AUROCC}^{\mathrm{c}}$} & \multicolumn{5}{|c|}{ Parameter statistics by PS component $^{\mathrm{d}}$} \\
\hline & & LR & $P$ & & PS & Estimate & SE & $P$ & Odds ratio \\
\hline \multirow[t]{2}{*}{$\overline{\mathrm{SHB}}$} & 156 & 55 & $<0.001$ & 0.70 & DS & -1.671 & 0.250 & $<0.001$ & 0.19 \\
\hline & & & & & MF & 0.005 & 0.002 & 0.006 & 1.01 \\
\hline \multirow[t]{3}{*}{ SHR } & 147 & 93 & $<0.001$ & 0.76 & Constant & -1.848 & 0.456 & $<0.001$ & $\ldots$ \\
\hline & & & & & CEM & -0.506 & 0.241 & 0.035 & 0.60 \\
\hline & & & & & WS & 0.649 & 0.085 & $<0.001$ & 1.91 \\
\hline \multirow[t]{3}{*}{ BS } & 143 & 92 & $<0.001$ & 0.76 & DS & 0.431 & 0.080 & $<0.001$ & 1.54 \\
\hline & & & & & $\mathrm{MF}$ & -0.005 & 0.002 & 0.008 & 0.99 \\
\hline & & & & & FP & -0.013 & 0.003 & $<0.001$ & 0.99 \\
\hline \multirow[t]{4}{*}{ LB } & 81 & 42 & $<0.001$ & 0.72 & Constant & -1.333 & 0.543 & 0.014 & $\ldots$ \\
\hline & & & & & DS & 0.351 & 0.095 & $<0.001$ & 1.42 \\
\hline & & & & & MF & -0.006 & 0.002 & 0.009 & 0.99 \\
\hline & & & & & $\mathrm{FP}$ & -0.007 & 0.003 & 0.016 & 0.99 \\
\hline \multirow[t]{4}{*}{ NB } & 83 & 36 & $<0.001$ & 0.71 & Constant & -1.732 & 0.526 & 0.001 & $\ldots$ \\
\hline & & & & & DS & -0.719 & 0.280 & 0.010 & 0.49 \\
\hline & & & & & WS & 0.386 & 0.094 & $<0.001$ & 1.47 \\
\hline & & & & & FP & -0.006 & 0.003 & 0.029 & 0.99 \\
\hline \multirow[t]{3}{*}{ BLB } & 46 & 39 & $<0.001$ & 0.75 & DS & 0.922 & 0.371 & 0.013 & 2.51 \\
\hline & & & & & WS & -0.221 & 0.109 & 0.042 & 0.80 \\
\hline & & & & & FP & -0.014 & 0.004 & $<0.001$ & 0.99 \\
\hline
\end{tabular}

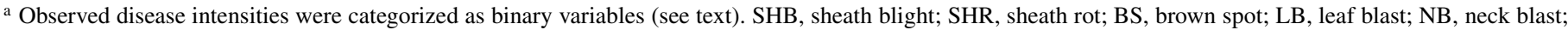
BLB, bacterial leaf blight. All diseases were represented in a binary form of disease intensity as follows: maximum SHB incidence on tillers throughout the cropping season $<10 \%, \mathrm{SHB}=0$ and $\geq 10 \%, \mathrm{SHB}=1$; maximum $\mathrm{SHR}$ incidence on panicles throughout the cropping season $<4 \%, \mathrm{SHR}=0$ and $\geq 4 \%$, SHR $=1$; area under BS incidence on leaves progress curve $<400 \%$.day, BS $=0$ and $\geq 400 \%$.day, BS $=1$; area under LB incidence on leaves progress curve $<10 \%$.day, $\mathrm{LB}=0$ and $\geq 10 \%$.day, $\mathrm{LB}=1$; maximum $\mathrm{NB}$ incidence on panicles throughout the cropping season $=0 \%, \mathrm{NB}=0$ and $\geq 0 \%, \mathrm{NB}=1 ;$ area under $\mathrm{BLB}$ incidence on leaves progress curve $<10 \%$.day, $\mathrm{BLB}=0$ and $\geq 10 \%$.day, $\mathrm{BLB}=1$.

b A case was defined as an individual farmer's field where disease exceeded the preset threshold (described in text).

c Area under the receiver operating characteristic curve.

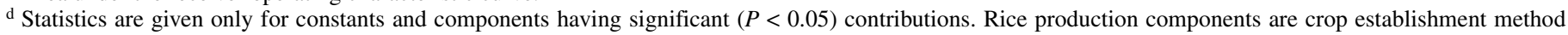
(DS), direct-seeding versus transplanting, statistics given for direct-seeding; water shortage (WS), accumulated water shortage ratings that were taken at four successive observations in each field; mineral fertilizer input (MF), cumulated, total $\mathrm{N}$, $\mathrm{P}$, and $\mathrm{K}$ inputs for a whole cropping season (kg ha ${ }^{-1}$ ); fallow period duration (FP), delay since the harvest of any crop prior to the observed rice crop (days); $\mathrm{SE}=$ standard error. 
dressed. Risk of S1 occurrence was positively associated with transplanted rice, low water shortage, increased mineral fertilizers, and long fallow periods (Fig. 2; Table 4), whereas S2 occurred more often under very short fallow-period durations and S3 was associated with intense water shortage, and also with both transplanted rice and low mineral fertilizer input. The largest corrected odds ratio in this series of analyses, which was fallow period as predictor of nonoccurrence of S2 with an odds ratio of 34.2 for a fallow period increased by 120 days, was an order of magnitude larger than any odds ratio estimated in the next series of analyses conducted for individual diseases.

Analyses using PSs as predictors of individual disease risks are given in Figure 3 and Table 5. The six diseases displayed different patterns of risk depending on PSs. For instance, SHB risk was positively and strongly associated with PS4, whereas BS risk was associated with PS3 and PS6. Risks for individual diseases were also often negatively associated with PSs; for example, SHR in PS1, PS4, PS5, and PS6.

In the fourth series of analyses, where diseases were predicted using individual components of PSs (Table 6; Fig. 4), the range of significant (at $P<0.05$ ) corrected odds ratios (1 to 5) was one order of magnitude smaller than when whole PSs were considered as predictors (Fig. 3; Table 5) (e.g., there was a 56-fold increase in the odds of LB epidemics not occurring when a field belongs to PS1 compared with a field belonging to the noclassPS category). Depending on the disease, different PS components predicted the risk of disease (Table 6; Fig. 4). For SHB, crop establishment method and level of mineral fertilizer were significant $(P<0.05)$ : direct-seeded rice decreased by a factor of 5.3 the SHB epidemic risk, while it was increased by 2.1 with increments of mineral fertilizer of $150 \mathrm{~kg} / \mathrm{ha}$ (Fig. 4). SHR risk decreased with directseeded rice and increased with water shortage. BS and LB had similar patterns of risk variation: an increase with water shortage and a decrease with higher fertilizer input and longer fallow periods. Risk of NB was increased by water shortage and de-

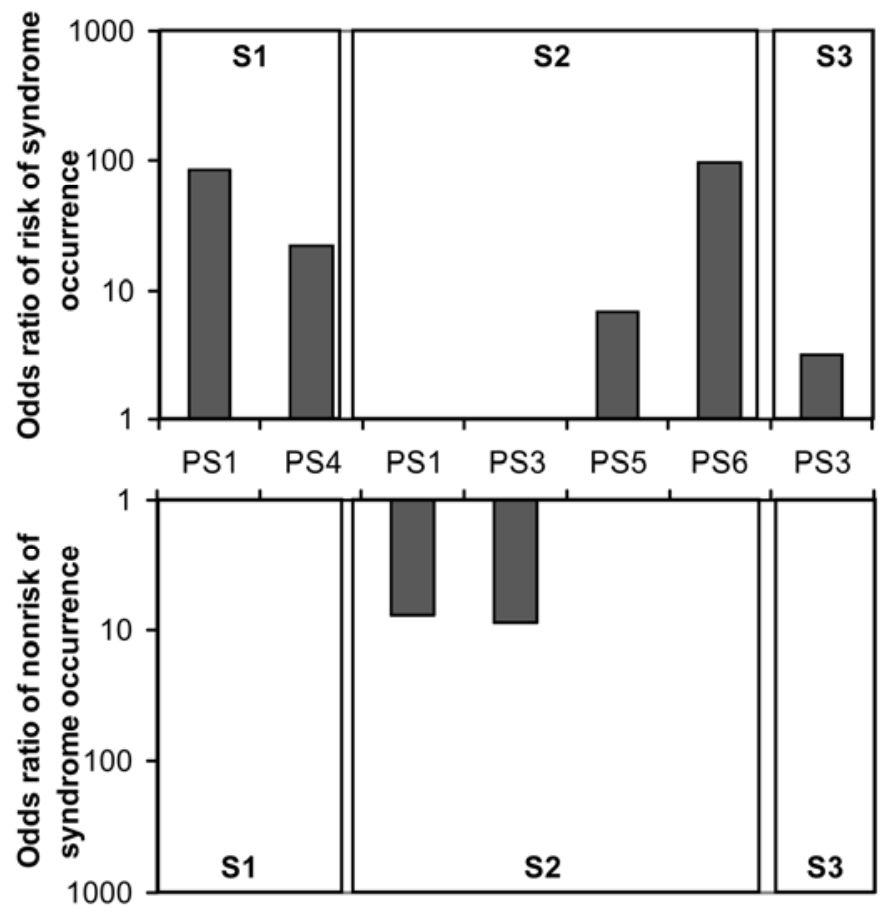

Fig. 1. Production situations (PSs) as risk factors for overall rice disease syndromes from logistic regressions. Only PSs with significant $(P<0.05)$ odds ratios are shown. Predictors for which odds ratios are $>1$ are displayed in the upper frame (increased risk); predictors with odds ratios $<1$ are represented as: (1/odds ratio) and displayed in the lower frame (decreased risk). PS1 to PS6: text and Table 1 provide details. S1, S2, and S3: syndromes of rice diseases (text and Table 2 provide details). creased in direct seeded rice and with long fallow periods. BLB risk increased in direct-seeded rice and decreased with water shortage and with long fallow periods. Note that the maximum corrected odds ratios obtained in this series of analyses were $<6$ and, in most cases, $<2.5$. One conclusion from this is that any individual components of PSs had a comparatively limited predictive ability for individual epidemic risks.

Development and evaluation of a predictor for future rice Ss. Based on predictions of S occurrence as a function of components of PSs, it was found that the likelihood of occurrence of the three Ss (S1, S2, and S3) were very well predicted by models involving crop establishment method, water shortage, mineral fertilizer input, and duration of fallow period as predictors (Table 7; Fig. 5). Likelihood ratios were $>240$ with associated probabilities $<0.001$, and area under ROC curves was $>0.85$. S1 was strongly (and negatively) associated with water shortage and (positively) with fallow period duration. S2 was strongly associated with crop establishment method (positive association with direct-seeded rice) and (negatively) with fallow period duration. S3 was positively associated with water shortage and negatively associated with direct-seeding, mineral fertilizer input, and fallow period duration. These models, which involve no constant in their equations, yielded results that are consistent with those derived from earlier logistic analyses (Fig. 2; Table 4).

For all three Ss, the results of Bayesian analyses were in agreement with results generated with the classical logistic regression models (Table 7). That is, in all cases where parameters were significant, logistic regressions and the Bayesian logistic analysis yielded means and standard errors of parameters that were very close. Thus, the parameter values estimated by standard logistic regression were within the 2.5 to $97.5 \%$ confidence interval produced by Bayesian analyses; the correspondence between the Bayesian parameter estimates and the standard estimates provided evidence of the robustness of the predictive logistic models.

Predicted shifts in $\mathrm{Ss}$ in response to shifts in components of PSs. Four drivers of change of PSs are considered in Figure 6: crop establishment (Fig. 6A), water shortage (Fig. 6B), mineral fertilizer input (Fig. 6C), and fallow period duration (Fig. 6D). Results are focused on four PSs (PS1, PS3, PS5, and PS6), which were represented by the largest sample sizes in the original data set.

The shift in crop establishment from transplanting to directseeding strongly and consistently increased the risk of occurrence of S2 in all PSs; the shift clearly decreased S3 but marginally increased $\mathrm{S} 1$.

Water shortage strongly affected Ss in PS5 and PS6, with a decrease of syndromes S1 and S2 and a large increase of S3. Increased water shortage also affected Ss in PS3, with a decrease of S1 and S2. Water shortage had comparatively limited effects on Ss in PS1, with an increase of S3.

The effects of shifts (decrease or increase) in mineral fertilizer input on changes in Ss were similar in all four PSs, although with large differences in magnitude. In PS1, a decrease of fertilizer input strongly enhanced S3 while an increase in inputs reduced $\mathrm{S} 3$. The other syndromes appeared to be unaffected with changed fertilizer input. The intensity of variation (positive or negative) in fallow period duration on shifts in Ss varied according to PSs, being very strong in PS1, lower in PS3 and PS5, and very small in PS6. In all PSs, a similar pattern was found, with a decreasing $(-50 \%)$ fallow period duration leading to much increased levels of $\mathrm{S} 2$, increases in S3, and slight decrease in S1. Small increases or decreases $( \pm 10 \%)$ of fallow period duration had small effects.

\section{DISCUSSION}

The research we report here examined a series of linked questions. A first question was whether there is evidence of linkage 
between PSs and Ss. A second question concerned the strength of relationships at different levels of hierarchy between PSs or their components and Ss or individual diseases. A third question was the basis on which to carry out predictive analyses of how Ss may change in response to changes in PSs arising from drivers of global change.

The first two questions were examined using an ecological hierarchy framework with various statistical approaches. Our results suggested that the observed pattern of Ss and PSs was not random, and that statistically significant linkages between diseases and production factors existed at each level of ecological organization. Specifically, and scaling down the considered hierarchy:

Top hierarchy level of allocation of rice fields among PSs and Ss. The occurrence of three predominant Ss (S1, S2, and S3) was predicted with high accuracy depending on the PS a field belongs to (Table 3; Fig. 1).

Intermediate hierarchy levels linking Ss with PS components or individual diseases with PSs. The accuracy of predictions was similar or lower than those obtained at the higher level of hierarchy. (Tables 4 and 5; Figs. 2 and 3).

Low levels linking individual diseases with individual PS components. The accuracy of prediction was generally lowest; nevertheless, statistically significant relationships between high disease levels (i.e., levels above preset thresholds) and individual PS components were found (Table 6; Fig. 4).
The approach used in this study enabled a hierarchy of relationships to be explored, taking the rice multiple pathosystem as a reference model. The succession of results obtained, with progressively stronger effects as one progresses up the organizational levels in the hierarchy, conforms to the principle that a system's behavior and properties (30) are more than the mere addition of its individual components (i.e., holons) (44). This phenomenon has recently been given an elegant conceptual basis by Frank (31): small-scale processes are generally subject to random noise; when small-scale processes are combined to form complex systems, random fluctuations in subsystems tend to cancel one another. As a result, observations made on the properties of complex systems tend toward a relatively small set of "limiting probability distributions" (e.g., Gaussian [normal], Poisson, Gamma, and power-law). These limiting (or emergent) distributions arise from the very structure of the information imposed by the sampling strategy used for measurements, and from whatever dominant signals survive the smearing process inherent in the aggregation of random processes. Our results are consistent with this view of how patterns emerge in biological systems. In this study, the lowest order of observations used expressed the largest amount of stochastic noise, and the level of noise decreased with increasing hierarchical structure in the data; this is reflected in the increase in odds ratios in the statistical models at successively higher hierarchical levels. This conformity to a theoretical model for general patterns is critical to predicting

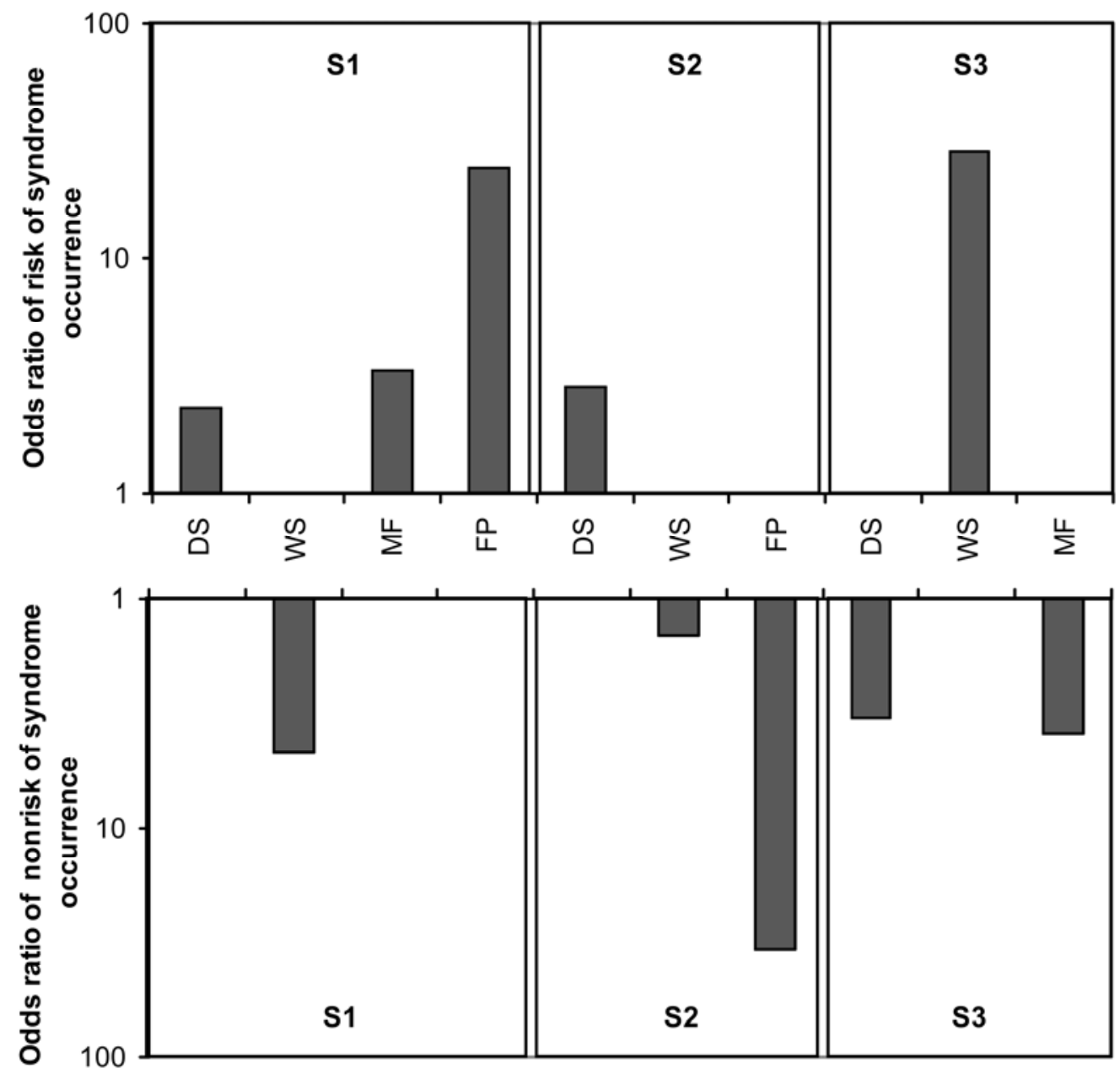

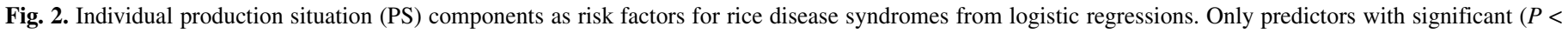

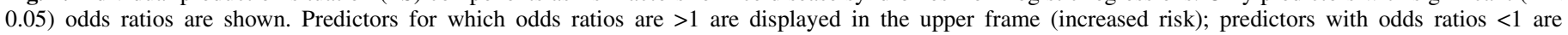

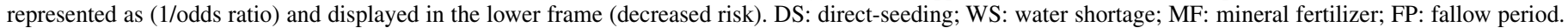

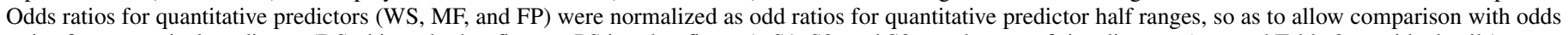
ratios for categorical predictors (DS, this and other figures; PS in other figures). S1, S2, and S3: syndromes of rice diseases (text and Table 2 provide details). 
future behavior in large-scale systems because it provides an expectation of anticipated general patterns. Essentially, each type of limiting probability distribution acts as an attractor for certain types of aggregate processes; therefore (in the current context), whereas global change may increase the level of noise arising from environmental factors, as long as the set of dominant processes generating disease and PS characteristics remains the same, broadly, the same types of pattern of connections should be anticipated in the future. Thus, "...each problem typically has a few constraints that set the pattern in the aggregate and all other fluctuations cancel as the non-constrained aspects tend to the greatest entropy or randomness....the final pattern reflects only the information content of the system expressed by the constraints on randomness; all else dissipates to the maximum entropy as the pattern converges to its limiting distribution defined by the informational constraints" (31).

The attraction to a pattern is reflected in the data analyzed here. At the lowest hierarchy level, empirical distributions of variables reflect constraints inherent to the sampling. Thus (Fig. 7), the distribution of measured actual field yields is near-normal, reflecting that each yield value is essentially an unconstrained deviation from the (unknown) mean yield of the population of rice fields. In contrast, SHB intensity (incidence) shows a skewed distribution, reflecting the fact that disease intensity is a ratio, constrained between upper and lower limits (31).

The cluster analyses used to derive the Ss and PSs (69) can be viewed as filtering processes that improved the signal-to-noise ratio in the data at the highest level of hierarchy. As a result, the predictive value of models is higher when using metavariables (i.e., cardinal, qualitative variables, that summarize the primary, field-based information) (65) than when using the primary variables. At lower levels of hierarchy, additional constraints imposed on the data operate among diseases themselves, because a host population (e.g., the rice crop) is essentially a finite resource, where niche number and size are limited (51). Our decomposition of the emergent multinomial distribution (limiting distribution) (31) for the data into a series of nested binomial regressions sacrifices parsimony in pursuit of comprehensibility.

Our scenario analyses (Fig. 6) indicated that a shift from transplanting to direct seeding will lead to increased occurrence of syndrome S2 (i.e., increased BS and BLB, and decrease in SHB) (Table 7); that more frequent water shortage will increase the likelihood of S3 (i.e., an increase of SHR, BS, LB, and NB); that increased fertilizer inputs will decrease S3; that decreased fertilizer inputs will increase S3; and that a shorter fallow prior to cultivation will increase $\mathrm{S} 2$. The disease-by-disease outcome of these analyses, at least for water scarcity and crop establishment, concur with the epidemiology of the considered diseases (64). They also provide new information on the effects of fallow period duration and fertilizer inputs on individual diseases. They further generate new information on risks associated with entire syndromes.

The current discourse on food security in the literature focuses on the technical constraints to closing the gap between actual and potential (77) crop yields. There is also emphasis of large gaps occurring because of farmers' inability to access inputs (including seed and knowledge) and to adapt to markets (38). We do not question that improved technology is part of the solution to global food security; indeed, this analysis suggests that changes of a small number of production factors are likely to have observable

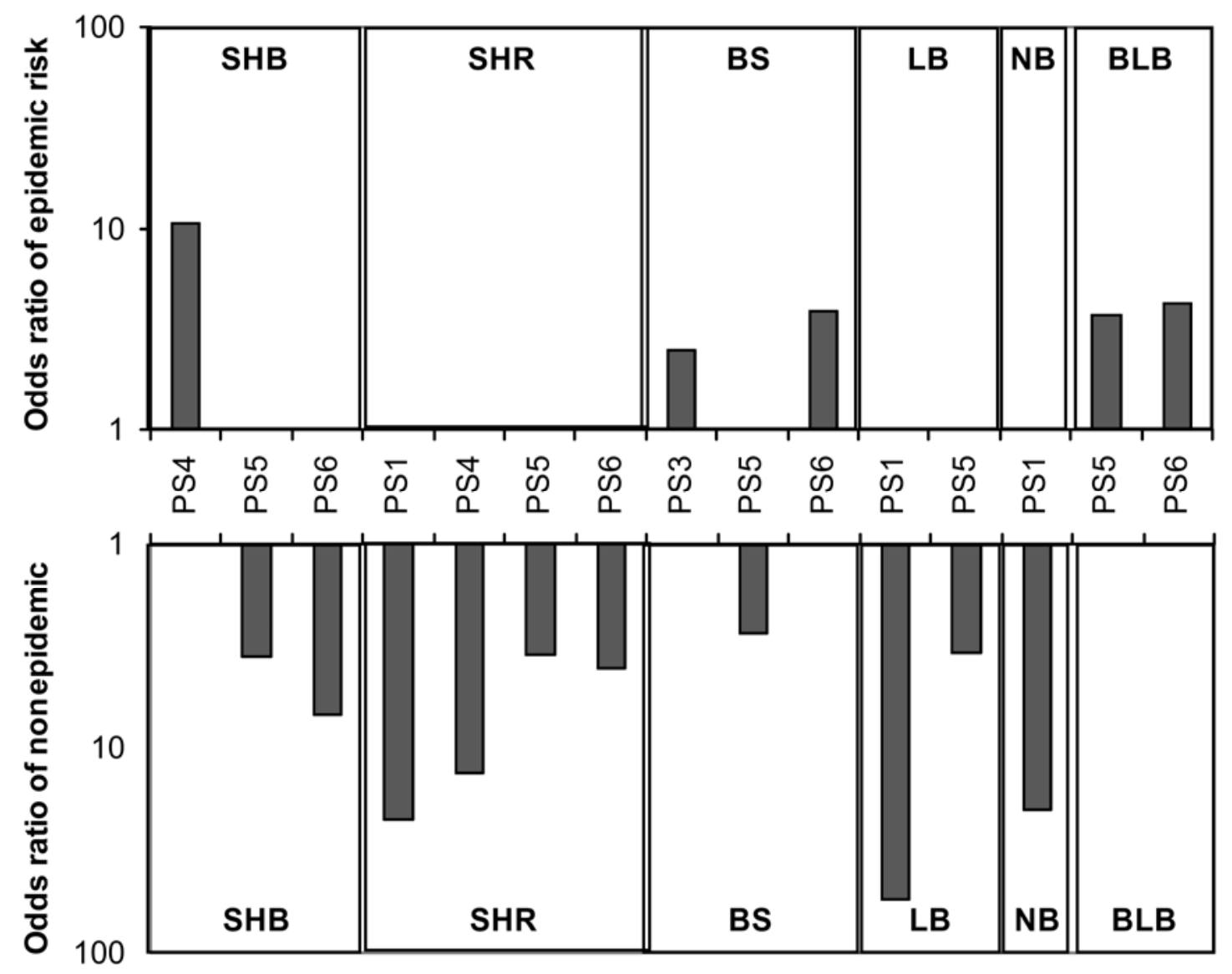

Fig. 3. Production situations (PSs) as risk factors for individual rice diseases from logistic regressions. Only PSs with significant $(P<0.05)$ odds ratios are shown. Predictors for which odds ratios are $>1$ are displayed in the upper frame (increased risk); predictors with odds ratios $<1$ are represented as: (1/odds ratio) and displayed in the lower frame (decreased risk). PS1 to PS6: text and Table 1 provide details. SHB: sheath blight; SHR: sheath rot; BS: brown spot; LB: leaf blast; NB: neck blast; BLB: bacterial leaf blight. All disease intensities were binarized according to preset thresholds (text provides details). 
effects on the composition and, thus, the impact of future Ss. However, Frank's (31) theoretical model cautions us not to expect profound, quantitative changes to occur in the extent of yield losses to diseases and pests. Rather, imposition of human man- agement on production systems can be thought of as increasing the deterministic (or "signal") component of the behavior of dynamic systems, while environmental processes only add stochastic noise. The behavior we observe (Fig. 6, actual yield and

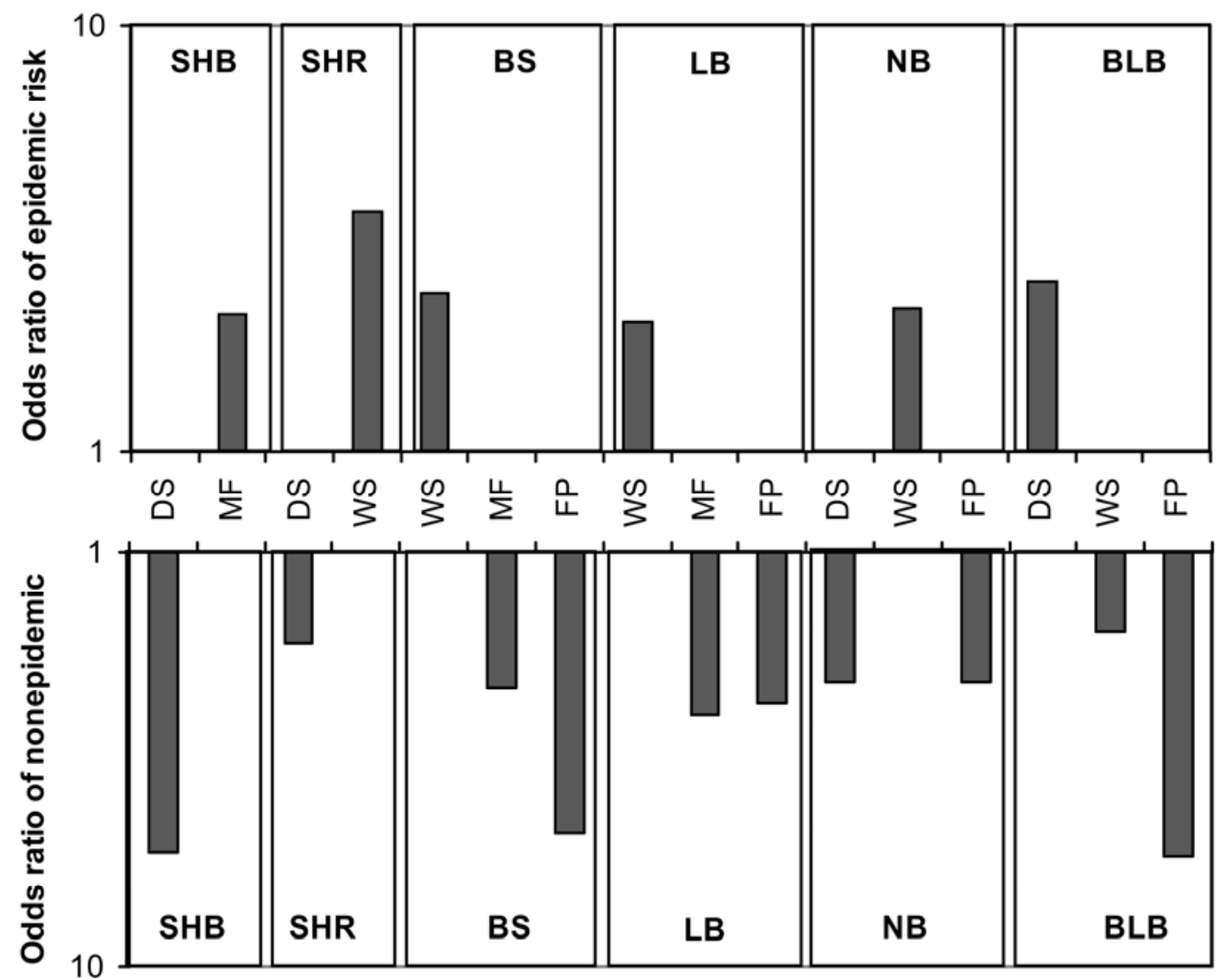

Fig. 4. Individual production situation (PS) components as risk factors for individual rice diseases from logistic regressions. Only predictors with significant $(P<$ 0.05 ) odds ratios are shown. Predictors for which odds ratios are $>1$ are displayed in the upper frame (increased risk); predictors with odds ratios $<1$ are represented as: (1/odds ratio) and displayed in the lower frame (decreased risk). DS: direct-seeding (as opposed to transplanting establishment method); WS: water shortage; MF: mineral fertilizer; FP: fallow period. Odds ratios for quantitative predictors (WS, MF, and FP) were normalized as odd ratios for quantitative predictor half ranges, so as to allow comparison with odds ratios for categorical predictors (for DS in this and other figures; and for PS in other figures). SHB: sheath blight; SHR: sheath rot; BS: brown spot; LB: leaf blast; NB: neck blast; BLB: bacterial leaf blight. All disease intensities were binarized according to preset thresholds (text provides details).

TABLE 7. Logistic regressions of occurrence of disease syndromes with four selected rice production situation (PS) components, without constant, from classical and Bayesian analyses

\begin{tabular}{|c|c|c|c|c|c|c|c|c|c|c|c|c|c|c|}
\hline \multirow[b]{3}{*}{ Syndrome ${ }^{\mathrm{a}}$} & \multicolumn{9}{|c|}{ Logistic regression } & \multirow{2}{*}{\multicolumn{5}{|c|}{ Bayesian logistic regression }} \\
\hline & \multicolumn{3}{|c|}{ Likelihood ratio $^{\mathrm{c}}$} & & \multicolumn{5}{|c|}{ Parameter statistics by PS component ${ }^{\mathrm{e}}$} & & & & & \\
\hline & Cases $^{\mathrm{b}}$ & LR & $P$ & AUROCC $^{\mathrm{d}}$ & PS & Estimate & SE & $P$ & Odds & Mean & SE & Median & $2.5 \%$ & $97.5 \%$ \\
\hline & & & & & WS & -0.932 & 0.083 & $<0.001$ & 0.39 & -0.953 & 0.084 & -0.952 & -1.118 & -0.797 \\
\hline & & & & & MF & 0.0004 & 0.001 & 0.768 & 1.00 & 0.0005 & 0.0015 & 0.0005 & -0.002 & 0.003 \\
\hline & & & & & FP & 0.0162 & 0.002 & $<0.001$ & 1.02 & 0.0163 & 0.002 & 0.0163 & 0.013 & 0.021 \\
\hline \multirow[t]{2}{*}{ S2 } & 108 & 288 & $<0.001$ & 0.86 & DS & 1.224 & 0.264 & $<0.001$ & 5.71 & 1.203 & 0.261 & 1.198 & 0.726 & 1.704 \\
\hline & & & & & FP & -0.0258 & 0.003 & $<0.001$ & 0.98 & -0.0264 & 0.0030 & -0.026 & -0.033 & -0.021 \\
\hline \multirow[t]{4}{*}{ S3 } & 123 & 328 & $<0.001$ & 0.91 & DS & -2.023 & 0.326 & $<0.001$ & 0.13 & -2.14 & 0.330 & -2.138 & -2.813 & -1.529 \\
\hline & & & & & WS & 1.034 & 0.111 & $<0.001$ & 2.81 & 1.063 & 0.140 & 1.063 & 0.864 & 1.260 \\
\hline & & & & & MF & -0.022 & 0.003 & $<0.001$ & 0.98 & -0.022 & 0.003 & -0.022 & -0.028 & -0.017 \\
\hline & & & & & FP & -0.0095 & 0.002 & $<0.001$ & 0.99 & -0.010 & 0.002 & -0.010 & -0.015 & -0.005 \\
\hline
\end{tabular}

a Table 2 provides definition of syndromes.

b Number of cases; a case was defined as an individual farmer's field where a given syndrome was observed.

${ }^{c}$ Statistics are shown for the complete model tested (four components of PSs, without constant).

${ }^{d}$ Area under the receiver operating characteristic curve. Statistics are shown for the complete model tested (four components of PSs, without constant).

e Rice PS components are crop establishment method (DS), direct-seeding versus transplanting, statistics given for direct-seeding; water shortage (WS), accumulated water shortage ratings that were taken at four successive observations in each field; mineral fertilizer input (MF), cumulated, total $\mathrm{N}$, $\mathrm{P}$, and $\mathrm{K}$ inputs for a whole cropping season $\left(\mathrm{kg} \mathrm{ha}^{-1}\right)$; fallow period duration (FP), delay since the harvest of any crop prior to the observed rice crop (days); $\mathrm{SE}=$ standard error; odds = odds ratio. 
SHB) at large scales is an emergent property of the interaction between these two types of processes. The patterns we observe today give us a good clue about the current behavior of a food production system, which stochastic component influences it, and what its dominant dynamics are. Therefore, this analysis informs us about the pattern we should expect in the future.

The idea that observed yield patterns and Ss reflect a balance between imposed deterministic and stochastic environmental processes was previously discussed (51), with two points directly related to this study. First, wider adoption of integrated pest management (IPM) was proposed, and viewed as a move toward managing complex, stochastic interactions occurring within agroecosystems and away from efforts to impose exogenous, deterministic control. Second, it was proposed that the theoretical basis for such an approach rests on the potential to manage niche competition to human advantage so that yield-reducing factors (diseases, animal pests, and weeds) are checked. This view of IPM allows us to see why some form of multinomial distribution emerges when crop health is addressed from an ecological niche point of view: a crop consists of a limited number of available sites, which may be occupied by disease (pests) (86). There is competition among pests to occupy each site, because there are guilds of harmful agents to a crop, which are the classes in the multinomial approach. Thus, competition or positive interaction may occur, which is expressed through syndromes whose makeup depends on environmental conditions, including human man-

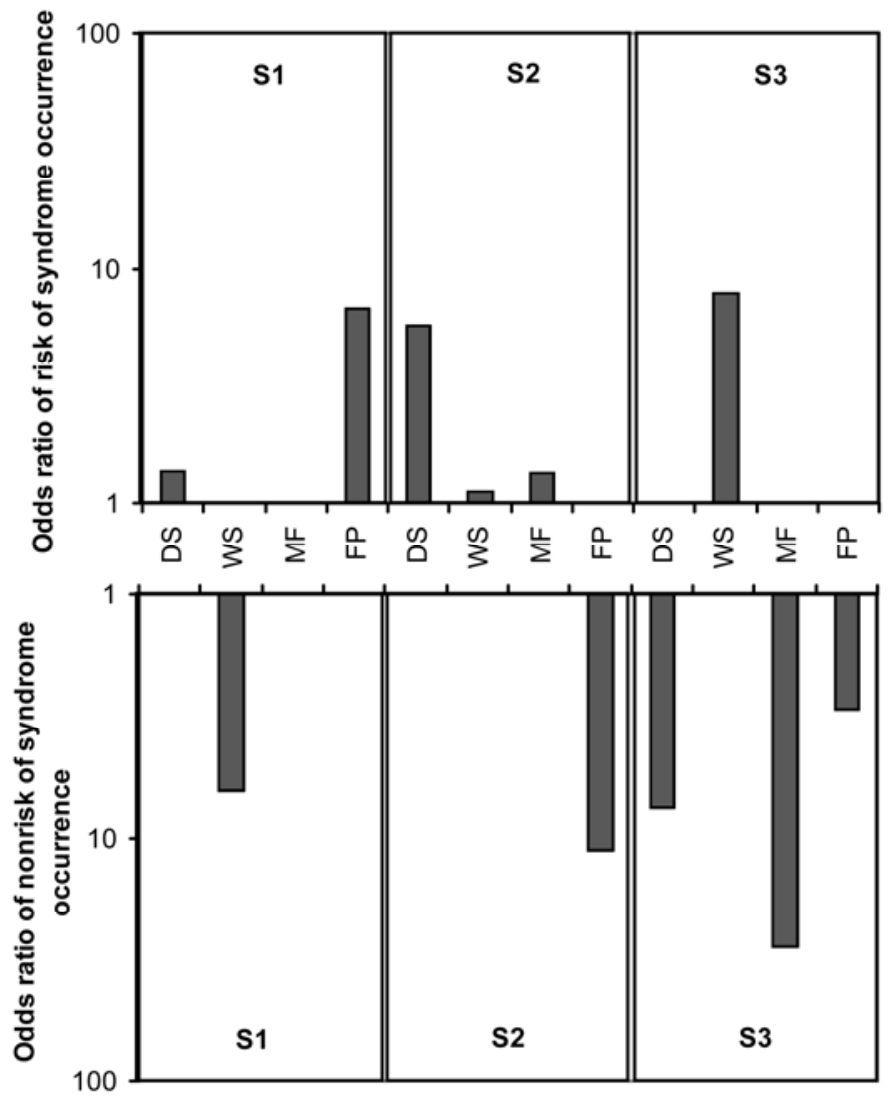

Fig. 5. Predicted risks associated with individual production situation (PS) components towards rice disease syndromes from logistic regressions. Odds for all predictors are shown, including those with non-significant $(P>0.05)$ odds ratios. Predictors for which odds ratios are $>1$ are displayed in the upper frame (increased risk); predictors with odds ratios $<1$ are represented as: (1/odds ratio) and displayed in the lower frame (decreased risk). DS: directseeding; WS: water shortage; MF: mineral fertilizer; FP: fallow period. Odds ratios for quantitative predictors (WS, MF, and FP) were normalized as odd ratios for quantitative predictor half ranges, so as to allow comparison with odds ratios for categorical predictors (DS, this and other figures; PS in other figures). S1, S2, and S3: syndromes of rice diseases (Table 2 provides details). agement. Site appropriation is further dependent on spatial aggregation; that is, characteristics of pests to spread. Spatial aggregation has been demonstrated to be the result of nested, hierarchical, processes $(50,83)$, with the generic consequence that, depending on the disease (pest), the number of available sites will vary over time and space and on the disease considered (83). This has been particularly well exemplified at the landscape level in the case of rice tungro disease (5), where synchronized crop establishment is a critical entry point for disease management.

The theoretical background (31) places our empirical results and statistical modeling firmly within an information-theoretic framework. Our use of Bayesian analysis further strengthens this empirical/theoretical connection. From an information theoretic and Bayesian perspective, knowledge about the state and behavior of a system is always viewed as a combination of prior belief and new information. The approach to the truth from prior ignorance is iterative, resulting from the accumulation of possibly contradictory pieces of evidence within a formal probabilistic framework. This approach is a rational one in the development of methods for assessing complex problems such as the issue of food security, where the demand for ex ante analysis is acute. A Bayesian approach allows us to construct initial analyses and predictions with the available information, and then update and refine these predictions as new evidence accumulates.

A range of research questions arises from these results. First, our analyses are based on current drivers of change affecting current PSs. Therefore, our scenario analyses did not address potential, entirely new syndromes, which might emerge in future PSs. Modeling approaches at the system level based on epidemiological knowledge of individual diseases might be considered to explore this question $(37,40,74)$. Nor did our analyses address individual, new, emerging diseases, which may, in the future, act in syndromes as the equivalent of keystone species (43) in natural systems. Different approaches involving simulation modeling $(37,85)$ or ecological niche modeling methods $(59,84)$ might be considered to address such questions. The above two types of questions may also, in part, be addressed by new data generated in a possibly wider array of PSs. A third area concerns the relationships between the drivers of agricultural change and the effects of climate change $(18,34)$ on diseases per se. These latter effects are only indirectly addressed in the present study, water shortage being the only driver of agricultural change that can be related to varying climate. Also, the very notion of PS does involve farmers' crop management and practices and, therefore, farmers' adaptation to variable climate (58). However, quantifying and predicting the respective role of direct climate variability and of the indirect effects of climate change on diseases and Ss remains a challenging research area (19).

Even though some diseases may today represent keystone (48) entities in syndromes, these results point to the need of managing rice diseases as syndromes, rather than individually, in a given PS. In many cases, especially for crops that contribute to global food security, disease management is likely to involve a range of components of PSs including, in the case of rice, improving seed health (52). These diverse options will complement the cornerstone of host plant resistance deployment (8), whenever this is available and durable.

The relationship between PS and S addressed in our analyses is analogous to relationships studied in human health. Public health epidemiologists have demonstrated in many instances the relationships between individual ways of life and their associated health risk problems. Predicting risk factors from individual habits (i.e., specific elements of ways of life) has been advocated to help disease prevention and guide research prioritization (10, 81 ). For instance, socioeconomic, environmental, and ecological environments have been shown to be strongly associated with patterns of emerging infectious diseases (42). Furthermore, shifts in ways of life have been shown to correspond to shifts in health 
A Change from Transplanted to Direct-seeded rice

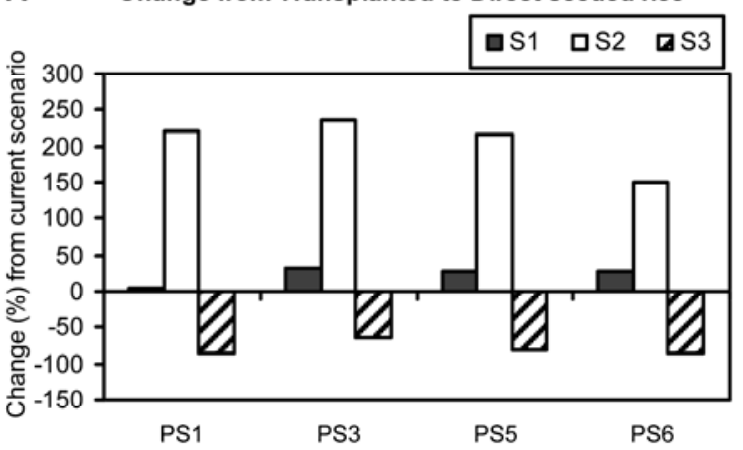

C

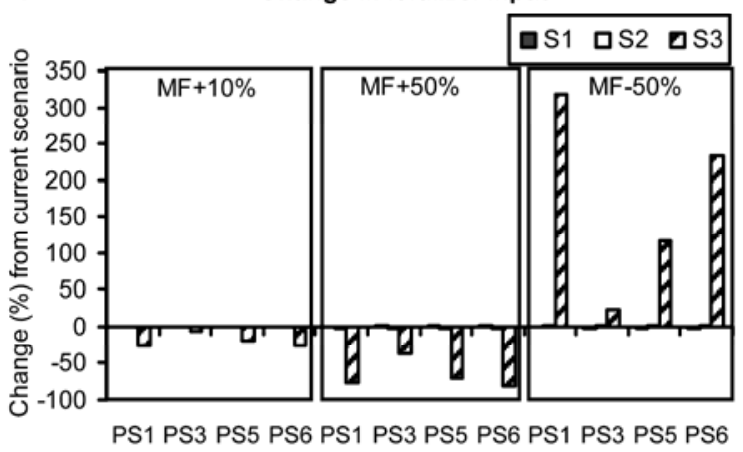

B

Change in water shortage

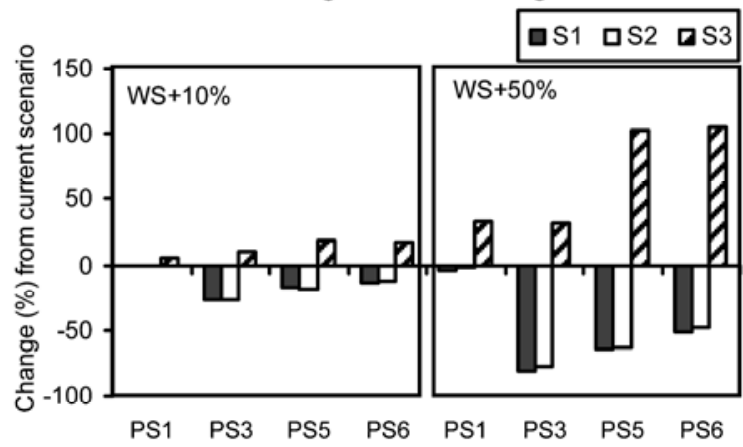

D

Change in fallow period duration

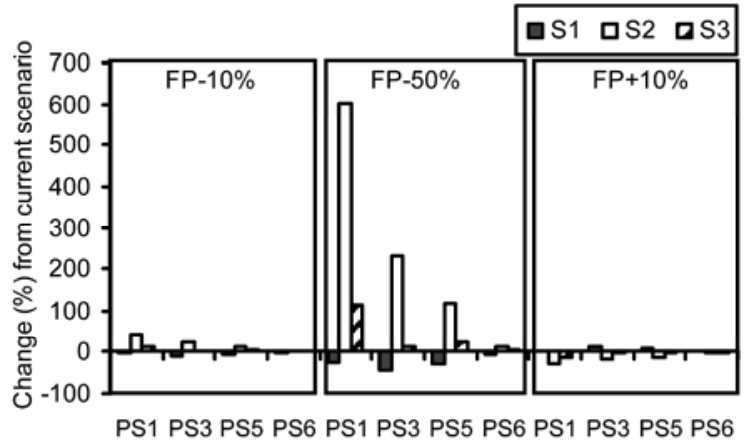

Fig. 6. Predicted changes in probability of occurrence of disease syndromes in response to shifts in components of production situations (PSs). Predicted changes in syndrome occurrence in response to changes in A, crop establishment; $\mathbf{B}$, water shortage (WS); $\mathbf{C}$, mineral fertilizer input (MF); and D, fallow period duration (FP). Only PS1, PS3, PS5, and PS6, which were represented by the largest sample sizes in the original data set, are considered. S1 to S3: disease syndromes 1 to 3, Table 2 provides description. PS1, PS3, PS5, and PS6: text and Table 1 provide details.
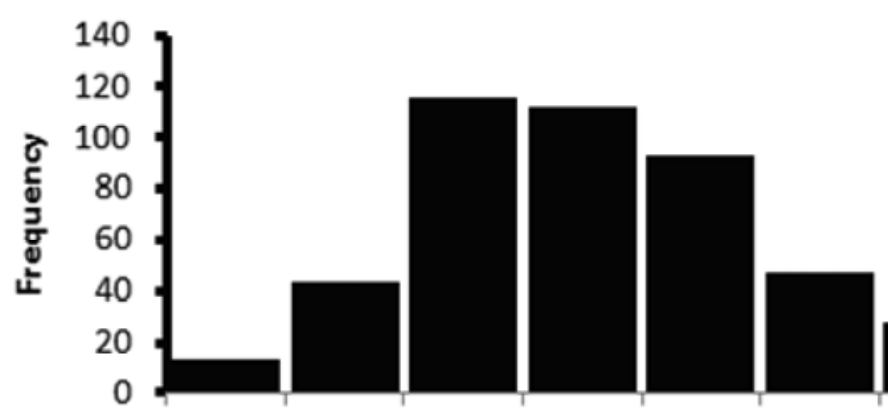

A

\subsection{5}

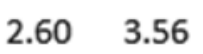

$4.51 \quad 5.47$

6.427 .38

8.33

9.29

Actual yield ( $t / h a ;$ label shows upper limit)

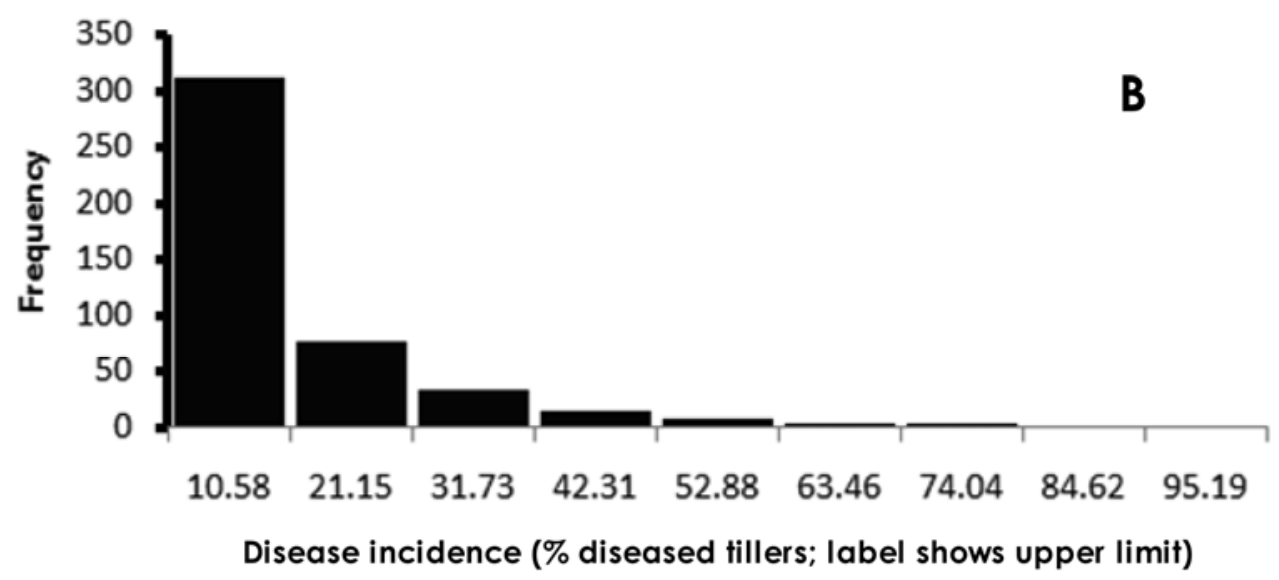

Fig. 7. Examples of empirical data distributions from the rice data set. A, Yield data showing approximately normal distribution. B, Disease incidence data for sheath blight displaying a right-skewed distribution. Both examples are consistent with the tendency toward a theoretical maximum entropy limiting distribution consistent with the constraints on information inherent in the sampling or assessment method employed to gather the data. 
problems (81). Examples include the association of obesity with shifts in diet and physical activity in modern societies (45), or the association of urbanization with the shift in burden of illness from acute childhood infections to chronic, noncommunicable diseases of adults (24). We hope that making this analogy explicit will alert both plant disease epidemiologists and policy makers to the idea that plant disease epidemiologists have a role to play in helping to achieve global food security that is analogous to the role played by human disease epidemiologists in securing increased levels of human health.

\section{ACKNOWLEDGMENTS}

Part of these results was presented at the American Phytopathological Society Meeting, 2008, St. Paul, MN. We thank North Carolina State University for support to M. Mila, IRRI for support to P. D. Esker and N. McRoberts, and reviewers for providing comments to improve the manuscript.

\section{LITERATURE CITED}

1. Agresti, A. 2002. Categorical Data Analysis, 2nd ed. John Wiley \& Sons, Hoboken, NJ.

2. Allen, T. H. F., and Starr, T. B. 1982. Hierarchy-Perspectives for Ecological Complexity. The University of Chicago Press, Chicago and London.

3. Anonymous, 2000. Report of the Secretary General: Linkages Between Agriculture, Land and Water. Economic and Social Council of the United Nations, Commission on Sustainable Development, Eighth Session. Sustainable Agriculture and Rural Development.

4. Arrow, K. J. 1994. Methodological individualism and social knowledge. Am. Econ. Rev. 84:1-9.

5. Azzam, O., and Chancellor, T. C. B. 2002. The biology, epidemiology, and management of rice tungro disease in Asia. Plant Dis. 86:88-100.

6. Bhuiyan, S. I., Tuong, T. P., and Wade, L. J. 1998. Management of water as a scarce resource: Issues and options in rice culture. Pages 175-192 in: Sustainability of Rice in the Global Food System. N. G. Dowling, S. M. Greenfield, and K. S. Fischer, eds. Pacific Basin Study Center, Davis, CA, and International Rice Research Institute, Manila, Philippines.

7. Bolker, B. M. 2008. Ecological Models and Data in R. Princeton University Press, Princeton, NJ.

8. Bonman, J. M., Khush, G. S., and Nelson, R. J. 1992. Breeding for resistance to pests. Annu. Rev. Phytopathol. 30:507-528.

9. Bouman, B. A. M., Humphreys, E., Tuong, T. P., and Barker, R. 2007. Rice and water. Adv. Agron. 92:187-237.

10. Breslow, L. 1978. Risk factor intervention for health maintenance. Science 200:908-912.

11. Butt, D. J., and Jeger, M. J. 1985. The practical implementation of models in crop disease management. Pages 207-230 in: Advances in Plant Pathology, Vol. 3. C. A. Gilligan, ed. Academic Press, London.

12. Carisse, O., Bacon, R., and Lefebvre, A. 2009. Grape powdery mildew (Erysiphe necator) risk assessment based on airborne conidium concentration. Crop Prot. 28:1036-1044.

13. Carisse, O., Jobin, T, and Bourgeois, G. 2008. Predicting apple leaf emergence from degree-day accumulation during the primary scab period. Can. J. Plant Sci. 88:229-238.

14. Carisse, O., Savary, S., and Willocquet, L. 2008. Spatiotemporal relationships between disease development and airborne inoculum in unmanaged and managed Botrytis leaf blight epidemics. Phytopathology 98:38-44.

15. Cassman, K. G., Dobermann, A., Walters, D. T., and Yang, H. S. 2003. Meeting cereal demand while protecting natural resources and improving environmental quality. Annu. Rev. Environ. Res. 28:315-358.

16. Castillo, P. S. 1962. A comparative study of directly-seeded and transplanted crops of rice. Philipp. Agric. 45:560-566.

17. Caswell, H. 2001. Matrix Population Models-Construction, Analysis, and Interpretation, 2nd ed. Sinauer, Sunderland, MA.

18. Chakraborty, S. 2005. Potential impact of climate change on plantpathogen interactions. Aust. Plant Pathol. 34:443-448.

19. Coakley, S. M., Scherm, H., and Chakraborty, S. 1999. Climate change and plant disease management. Annu. Rev. Phytopathol. 37:399-426.

20. Daamen, R. A., and Rabbinge, R. 1991. Risks, forecasting and tactical decision-making in integrated pest and disease management. OEPP Bull. 21:461-467.

21. De Wit, C. T. 1982. Simulation of living systems. Pages 1-8 in: Simulation of Plant Growth and Crop Production. F. W. T. Penning de Vries, and H. H. Van Laar, eds. Pudoc, Wageningen, The Netherlands.

22. Dowling, N. G., Greenfield, S. M., and Fischer, K. S. (Eds.) 1998.
Sustainability of Rice in the Global Food System. Pacific Basin Study Center, Davis, CA and International Rice Research Institute, Manila, Philippines.

23. Draper, N., and Smith, H. 1981. Applied Regression Analysis, 2nd Edition. John Wiley \& Sons, New York.

24. Dye, C. 2008. Health and urban living. Science 319:766-769.

25. Dyson, T. 1999. World food trends and prospects to 2025. Proc. Natl. Acad. Sci. USA 96:5929-5936.

26. Esker, P. D., Harri, J., Dixon, P. M., and Nutter, F. W., Jr. 2006. Comparison of models for forecasting of Stewart's disease of corn in Iowa. Plant Dis. 90:1353-1357.

27. Evenson, D. E., and Gollin, D. 2003. Assessing the impact of the green revolution, 1960 to 2000 . Science 300:758-762.

28. Fabre, F., Dedryver, C. A., Leterrier, J. L., and Plantegenest, M. 2003. Aphid abundance on cereals in autumn predicts yield losses caused by Barley yellow dwarf virus. Phytopathology 93:1217-1222.

29. Foley, J. A., DeFries, R., Asner, G. P., Barford, C., Bonan, G., Carpenter, S. R., Chapin, S., Coe, M. T., Daily, G. C., Gibbs, H. K., Helkowski, J. H., Holloway, T., Howard, E. A., Kucharik, C. J., Monfreda, C., Patz, J. A., Prentice, I. C., Ramankutty, N., and Snyder, P. K. 2005. Global consequences of land use. Science 305:570-574.

30. Forrester, J. W. 1961. Industrial Dynamics. M.I.T. Press, Cambridge, MA.

31. Frank, S. A. 2009. The common patterns of nature. J. Evol. Biol. 22:15631585.

32. Frank, S. A., and Smith D. E. 2010. Measurement invariance, entropy and probability. Entropy 12:289-303.

33. Fresco, L. O., and Kroonberg, S. B. 1992. Time and spatial scales in ecological sustainability. Land Use Policy 9:155-168.

34. Garrett, K. A., Dendy, S. P., Frank, E. E., Rouse, M. N., and Travers, S. E. 2006. Climate change effects on plant disease: Genomes to ecosystems. Annu. Rev. Phytopathol. 44:489-509.

35. Gelman, A., Carlin, J. B., Stern, H. S., and Rubin, D. B. 1996. Bayesian Data Analysis. Chapman \& Hall, CRC Press, Boca Raton, FL.

36. Giampietro, M. 2003. Multiscale Integrated Analysis of Agroecosystems. CRC Press, Boca Raton, FL.

37. Gilligan, C. A., and Van den Bosch, F. 2008. Epidemiological models for invasion and persistence of pathogens. Annu. Rev. Phytopathol. 46:385418.

38. Godfray, H. C. J., Beddington, J. R., Crute, I. R., Haddad, L., Lawrence, D., Muir, J. F., Pretty, J., Robinson, S., Thomas, S. M., and Toulmin, C. 2010. Food security: The challenge of feeding 9 billion people. Science 327:812-818.

39. Greenland, D. J. 1997. The Sustainability of Rice Farming. CABI, Wallingford, UK, and IRRI, Manila, Philippines.

40. Gutierrez, A. P., Gilioli, G., and Baumgärtner, J. 2009. Ecosocial consequences and policy implications of disease management in East African agropastoral systems. Proc. Natl. Acad. Sci. USA 106:1313613141.

41. Harrell, F. E., Jr. 2001. Regression Modeling Strategies: With Applications to Linear Models, Logistic Regression, and Survival Analysis. Springer-Verlag, New York.

42. Jones, K. E., Patel, N. G., Levy, M. A, Storeygard, A., Balk, D., Gittleman, J. L., and Daszak, P. 2008. Global trends in emerging infectious diseases. Nature 451:990-993.

43. Jordan, F. 2009. Keystone species and food webs. Philos. Trans. R. Soc. B 364:1733-1741.

44. Koestler, A. 1967. The Ghost in the Machine. Hutchinson \& Co. and Arkana-Penguin Group, London and New York.

45. Kopelman, P. G. 2000. Obesity as a medical problem. Nature 404:635643.

46. Krause, R. A., and Massie, L. B. 1975. Predictive systems: Modern approaches to disease control. Annu. Rev. Phytopathol. 13:31-47.

47. Krause, R. A., Massie, L. B., and Hyre, R. A. 1975. Blitecast: A computerized forecast of potato late blight. Plant Dis. Rep. 59:95-98.

48. Loreau, M., Naeem, S., Inchausti, P., Bengtsson, J., Grime, J. P., Hector, A., Hooper D. U., Huston, M. A., Raffaelli, D., Schmid, B., Tilman, D., and Wardle D. A. 2001. Biodiversity and ecosystem functioning: Current knowledge and future challenges. Science 294:804-808.

49. MacHardy, W. E. 1996. Apple Scab: Biology, Epidemiology, and Management. American Phytopathological Society Press, St. Paul, MN.

50. McRoberts, N., Hughes, G., and Madden, L. V. 2003. The theoretical basis and practical application of relationships between different disease intensity measurements in plants. Ann. Appl. Biol. 142:191-211.

51. McRoberts, N., Hughes, G., and Savary, S. 2003. Integrated approaches to understanding and control of diseases and pests in field crops. Aust. Plant Pathol. 32:167-180.

52. Mew, T. W., and Hossain, M. (Eds.) 2008 Seed Health Improvement for Pest Management and Crop Production. Limited Proc. No. 13, IRRI, Los Baños, Philippines.

53. Mila, A. L., and Carriquiry, A. L. 2004. Bayesian analysis in plant 
pathology. Phytopathology 94:1027-1030.

54. Mila, A. L., and Michailides, T. J. 2006. Use of Bayesian methods to improve prediction of panicle and shoot blight severity in pistachio in California. Phytopathology 96:1142-1147.

55. Mila, A. L., Yang, X. B., and Carriquiry, A. L. 2003. Bayesian logistic regression of soybean Sclerotinia stem rot prevalence in the US northcentral region: Accounting for uncertainty in parameter estimation. Phytopathology 93:758-764.

56. Oerke, E. C. 2006. Crop losses to pests. J. Agric. Sci. 144:31-43.

57. Palti, J. 1981. Cultural Practices and Infectious Crop Diseases. Springer Verlag, Berlin, Heidelberg, New York.

58. Pardey, P. G., Alston, J. M., and Piggot, R. R. 2006. Agricultural R\&D in the Developing World: Too Little, Too Late? International Food Policy Research Institute, Washington, DC.

59. Peterson, A. T. 2006. Ecologic niche modeling and spatial patterns of disease transmission. Emerg. Infect. Dis. 12:1822-826.

60. Pingali, P., and Hossain, M., eds. 1998. Impact of Rice Research. Thailand Development Research Institute, Bangkok, Thailand, and International Rice Research Institute, Manila, Philippines.

61. Pretty, J. 2008. Agricultural sustainability: Concepts, principles and evidence. Philos. Trans. R. Soc. B 363:447-465.

62. Rabbinge, R., Van Diepen, C. A., Dijsselbloem, J., De Koning, G. J. H., Van Latesteijn, H. C., Woltjer, E., and Van Zijl, J. 1994. 'Ground for Choices': A scenario study on perspectives for rural areas in the European Community. Pages 95-121 in: The Future of the Land: Mobilising and Integrating Knowledge for Land Use Options. L. O. Fresco, L. Stroosnijder, J. Bouma, and H. Van Keulen, eds. John Wiley, Chichester, UK.

63. Savary, S., Castilla, N. P., Elazegui, F. A., McLaren, C. G., Ynalvez, M. A., and Teng, P. S. 1995. Direct and indirect effects of nitrogen supply and disease source structure on rice sheath blight spread. Phytopathology 85:959-965.

64. Savary, S., Castilla, N. P., Elazegui, F. A., and Teng, P. S. 2005. Multiple effects of two drivers of agricultural change, labour shortage and water scarcity, on rice pest profiles in tropical Asia. Field Crops Res. 91:263271.

65. Savary, S., Madden, L. V., Zadoks, J. C., and Klein-Gebbinck, H. W. 1995. Use of categorical information and correspondence analysis in plant disease epidemiology. Adv. Bot. Res. incorporating Adv. Plant Pathol. 21:213-240.

66. Savary, S., Mille, B., Rolland, B., and Lucas, P. 2006. Patterns and management of crop multiple pathosystems. Pages 123-138 in: Plant Disease Epidemiology: Facing Challenges of the 21st Century. S. Savary, and B. M. Cooke, eds. Springer, Dordrecht, The Netherlands.

67. Savary, S., Teng, P. S., Willocquet, L., and Nutter, F. W. Jr. 2006. Quantification and modeling of crop losses: A review of purposes. Annu. Rev. Phytopathol. 44:89-112.

68. Savary, S., Willocquet, L., Elazegui, F. A., Castilla, N., and Teng, P. S. 2000. Rice pest constraints in tropical Asia: Quantification of yield losses due to rice pests in a range of production situations. Plant Dis. 84:357369.

69. Savary, S., Willocquet, L., Elazegui, F. A., Teng, P. S., Du, P. V., Zhu, D., Tang, Q., Huang, S., Lin, X., Singh, H. M., and Srivastsava, R. K. 2000.
Rice pest constraints in tropical Asia: Characterization of injury profiles in relation to production situations. Plant Dis. 84:341-356.

70. Smil, V. 2000. Feeding the World. A Challenge for the Twentieth Century. The MIT Press, Cambridge, MA.

71. Smith, I. M. 1991. Regulatory aspects of plant protection. Pages 243-251 in: Modern Crop Protection: Development and Perspectives. J. C. Zadoks, ed. Wageningen Pers, Wageningen, The Netherlands.

72. Spriegelhalter, D. J., Thomas, A., Best, N., and Gilks, W. R. 1995. BUGS: Bayesian inference using Gibbs sampling, version 0.50. Technical Report, Medical Research Council Biostatistics Unit, Institute of Public Health, Cambridge University, UK.

73. Steinberg, D., and Colla, P., 2007. Logistic regression. Pages 2-92 in: Statistics III, SYSTAT 12. SYSTAT Software, Inc., San Jose, CA

74. Teng, P. S., Savary, S., and Revilla, I. 1993. Systems of plant protection. Pages 116-139 in: Crop Protection and Sustainable Agriculture. Ciba Foundation Symposium 177. Wiley, Chichester, UK.

75. Turchin, P. 2003. Complex Population Dynamics: A Theoretical/ Empirical Synthesis. Princeton University Press, Princeton, NJ.

76. Van der Heijden, P. G. M., de Falguerolles, A., and De Leeuw, J. 1989. A combined approach to contingency table analysis using correspondence analysis and log-linear analysis. Appl. Stat. 38:249-292.

77. Van Ittersum, M. K., and Rabbinge, R. 1997. Concepts in production ecology for analysis and quantification of agricultural input-output combinations. Field Crops Res. 52:197-208.

78. Vitousek, P. M., Mooney, H. A., Lubchenco, J., and Melillo, J. M. 1999. Human domination of earth's ecosystems. Science 277:494-499.

79. Vörösmarty, C. J., Green, P., Salisbury, J., and Lammers, R. B. 2000. Global water resources: Vulnerability from climate change and population growth. Science 289:284-288.

80. Walker, B. H., and Steffen, W. L. 1999. The nature of global change. Pages 1-18 in: The Terrestrial Biosphere and Global Change. Implications for Natural and Managed Ecosystems. B. H. Walker, W. L. Steffen, J. Canadell, and J. Ingram, eds. Cambridge University Press, Cambridge, UK.

81. Willett, W. C. 2002. Balancing life-style and genomics research for disease prevention. Science 296:695-698.

82. Willocquet, L., Fernandez, L., and Savary, S. 2000. Effect of various crop establishment methods practiced by Asian farmers on epidemics of rice sheath blight caused by Rhizoctonia solani. Plant Pathol. 49:346-354.

83. Willocquet, L., and Savary, S. 2004. An epidemiological simulation model with three scales of spatial hierarchy. Phytopathology 94:883-891.

84. Wisz, M. S., Hijmans, R. J., Li, J., Peterson, A. T., Graham, C. H., and Guisan, A. 2008. Effects of sample size on the performance of species distribution models. Divers. Distrib. 14:763-773.

85. Yang, X. B., Dowler, W. M., and Royer, M. H. 1991.Assessing the risk and potential impact of an exotic plant disease. Plant Dis. 75:976-982.

86. Zadoks, J. C. 1971. Systems analysis and the dynamics of epidemics. Phytopathology 61:600-610.

87. Zadoks, J. C. 1985. On the conceptual basis of crop loss assessment: The threshold theory. Annu. Rev. Phytopathol. 23:455-473.

88. Zadoks, J. C., and Schein, R. D. 1979. Epidemiology and Plant Disease Management. Oxford University Press, New York.

89. Zeigler, R. S., and Barclay, A. 2008. The relevance of rice. Rice 1:3-10. 